\title{
Article \\ Structural Properties and Magnetic Ground States of 100 Binary $d$-Metal Oxides Studied by Hybrid Density Functional Methods
}

\author{
Mikhail S. Kuklin, Kim Eklund, Jarno Linnera, Artturi Ropponen (D), Nikolas Tolvanen and Antti J. Karttunen * (D)
}

Department of Chemistry and Materials Science, Aalto University, FI-00076 Aalto, Finland; mikhail.kuklin@aalto.fi (M.S.K.); kim.eklund@aalto.fi (K.E.); jarno.linnera@aalto.fi (J.L.)

* Correspondence: antti.karttunen@aalto.fi

\section{check for}

updates

Citation: Kuklin, M.S.; Eklund, K.;

Linnera, J.; Ropponen, A.; Tolvanen,

N.; Karttunen, A.J. Structural

Properties and Magnetic Ground

States of 100 Binary $d$-Metal Oxides

Studied by Hybrid Density

Functional Methods. Molecules 2022

27, 874. https://doi.org/10.3390/

molecules27030874

Academic Editors: Marek Cypryk

and Piotr Paneth

Received: 31 December 2021

Accepted: 24 January 2022

Published: 27 January 2022

Publisher's Note: MDPI stays neutral with regard to jurisdictional claims in published maps and institutional affiliations.

Copyright: (C) 2022 by the authors. Licensee MDPI, Basel, Switzerland. This article is an open access article distributed under the terms and conditions of the Creative Commons Attribution (CC BY) license (https:// creativecommons.org/licenses/by/ $4.0 /)$.

\begin{abstract}
: $d$-metal oxides play a crucial role in numerous technological applications and show a great variety of magnetic properties. We have systematically investigated the structural properties, magnetic ground states, and fundamental electronic properties of 100 binary $d$-metal oxides using hybrid density functional methods and localized basis sets composed of Gaussian-type functions. The calculated properties are compared with experimental information in all cases where experimental data are available. The used PBE0 hybrid density functional method describes the structural properties of the studied $d$-metal oxides well, except in the case of molecular oxides with weak intermolecular forces between the molecular units. Empirical D3 dispersion correction does not improve the structural description of the molecular oxides. We provide a database of optimized geometries and magnetic ground states to facilitate future studies on the more complex properties of the binary $d$-metal oxides.
\end{abstract}

Keywords: oxides; transition metals; magnetism; computational chemistry; density functional theory

\section{Introduction}

$d$-metal oxides play a crucial role in many technological applications [1-8]. In particular, they find use in electronics [2,3,5], thermoelectrics [6,8], and applications related to their magnetic properties [7]. In addition to bulk metal oxide materials, oxide thin films possess unique properties due to their thickness-dependent properties which are widely known in catalysis [1-4]. Many of the $d$-metal oxides are magnetic, which complicates both experimental and computational studies. For example, magnetic structures of the $d$-metal oxides cannot be solved by ordinary $X$-ray techniques but require neutron diffraction or special techniques such as resonant $X$-ray scattering. In computational studies, open-shell magnetic compounds pose a challenge for methods based on density functional theory (DFT).

It is well known that DFT methods such as DFT-PBE, where the exchange-correlation functional is based on the generalized gradient approximation (GGA), fail in describing magnetic and electronic structures of strongly correlated $d$-metal oxides, sometimes even leading to a wrong magnetic ground state [9-16]. Even in the case of diamagnetic $d$-metal oxides such as $\mathrm{Cu}_{2} \mathrm{O}$, DFT-GGA may describe the electronic properties rather poorly, resulting in a poor description of other properties such as phonons [17]. These challenges arise from the self-interaction error of DFT-GGA, resulting from the over-delocalization of the electrons in the metal $d$ orbitals, in particular $3 d$ orbitals [9,18-21]. As a result, the electronic structure can be even qualitatively wrong. This problem can be partially solved by using the Hubbard parameter $(U)$ which localizes the electrons on the $d$-metal atoms [22]. However, even GGA $+U$ underestimates band gaps of $d$-metal monoxides $[18,23]$. Furthermore, in addition to the problem with the $d$-metal orbitals, a similar issue with over-delocalization affects the oxygen $2 p$ orbitals; in which case, the $U$ correction does not help to overcome the problem [24]. Recently, promising results on magnetic $\mathrm{La}_{2} \mathrm{CuO}_{4}$ and $\mathrm{VO}_{2}$ were obtained 
by meta-GGA DFT-SCAN functional [25-27]. However, at the same time, it was shown that the treatment of the electronic structure of semiconducting and insulating materials by DFT-SCAN are typically not improved over DFT-GGA [28-30].

Hybrid density functionals that incorporate some exact exchange are known to significantly correct the self-interaction error, leading to correct description of the electronic and magnetic structures $[15,18,20,21,24,31-33]$. In particular, the main improvement of hybrid functionals over GGA functionals is the correct treatment of the valence bands near the Fermi level, leading to correct localization of the electrons [15,21]. The structural and electronic properties are typically described reasonably well, even if the band gap is generally overestimated $[34,35]$. Approaches to further improve the band gap prediction of hybrid functionals have also been suggested: dielectric-dependent hybrid functionals do not show real improvement, but the application of so-called charge transition level scheme leads to the further improvement of the predicted band gaps [36,37]. In principle, it is possible to tune the band gap predictions by tuning the amount of exact exchange, but such an empirical approach deteriorates the predictive power of the methodology [21]. In general, hybrid functionals with about $25 \%$ exact exchange such as PBE0 have been shown to describe $d$-metal oxides and their magnetic structures reasonably well $[15,21,24,31]$. The screened hybrid functionals such as HSE06 are another very commonly used approach in solid-state DFT studies, and they have been shown to predict band gaps of $d$-metal oxides and dichalcogenides with good accuracy [38].

Even though a vast number of computational studies on binary $d$-metal oxides have been reported in the literature, most of them have included only some subset of the binary $d$-metal oxides, and a comparison of the results is complicated by the variety of used computational methodologies. A comprehensive dataset of the structural properties and magnetic ground states of binary $d$-metal oxides, obtained with a DFT method that can properly describe the electronic structures of strongly correlated oxides, would facilitate future studies on more complex properties and eventual material applications. As an example of data analytics enabled by such datasets, Posysaev et al. recently investigated the oxidation states of a number of binary oxides taken from the AFLOW library [39]. Examples of physical and transport properties that can be nowadays accessed routinely with hybrid DFT methods are elastic, dielectric, piezoelectric, and thermoelectric properties [40].

Here, we present a comprehensive computational investigation of $d$-metal oxides known at the atmospheric pressure by using the hybrid DFT-PBE0 method (see Materials and Methods for computational details). We focus on binary $d$-metal oxides such as $\mathrm{Fe}_{2} \mathrm{O}_{3}$ and $\mathrm{CuO}$ and rule out ternary $d$-metal oxides such as $\mathrm{FeTiO}_{3}$ or $\mathrm{CoTiO}_{3}$. We studied in total 100 binary $d$-metal oxides, reporting their structural properties and magnetic ground states, including magnetic ground states at $0 \mathrm{~K}$ for materials that were reported to be paramagnetic at room temperature. We also investigate the effect of DFT-D3 dispersion correction on structural properties of molecular $d$-metal oxides [41]. We report the performance of the DFT-PBE0 method for binary $d$-metal oxides and provide a freely available dataset that enables further studies on their spectroscopic, mechanical, dielectric, and transport properties.

\section{Results and Discussion}

\subsection{General Overview of the Results}

We considered in total 100 binary d-metal oxides that are known to exist at the atmospheric pressure. We distinguished the studied oxides by their structural formula and Pearson symbol. Several $d$-metal oxides have high-temperature polymorphs which were included if they possessed an ordered crystal structure. High-pressure modifications were excluded from the present study. In the main text, we discuss only the magnetic oxides in detail, while results for nonmagnetic oxides are provided in the Supplementary Materials.

Table 1 lists the Pearson symbols, space groups, magnetic ground states, magnetic moments, and band gaps of the studied magnetic $d$-metal oxides. As discussed above, it is known that hybrid DFT methods may typically overestimate band gaps. Furthermore, our 
calculated band gaps are for perfect single crystals at $0 \mathrm{~K}$, while the experimental band gaps are typically reported for room temperature and might depend significantly on the sample type (single crystal, polycrystalline, and thin film). Therefore, qualitative comparisons with the experimental results (insulating vs. metallic nature) are here more relevant than quantitative comparisons.

Table 1. Pearson symbols, space groups, magnetic ground states, spin magnetic moments for the metal atoms $\left(\mu_{\mathrm{B}}\right)$, and band gaps of the studied magnetic binary $d$-metal oxides.

\begin{tabular}{|c|c|c|c|c|c|c|c|c|}
\hline \multirow{2}{*}{ Oxide } & \multirow{2}{*}{$\begin{array}{l}\text { Pearson } \\
\text { Symbol }^{\text {a }}\end{array}$} & \multirow{2}{*}{$\begin{array}{c}\text { Space Group of } \\
\text { Nonmagnetic } \\
\text { Unit Cell }\end{array}$} & \multirow{2}{*}{$\begin{array}{c}\text { Space Group of } \\
\text { Magnetic Unit } \\
\text { Cell }\end{array}$} & \multirow{2}{*}{$\begin{array}{l}\text { Magnetic } \\
\text { Ground } \\
\text { State }{ }^{b}\end{array}$} & \multicolumn{2}{|c|}{ Magnetic Moment $\left(\mu_{B}\right)^{c}$} & \multicolumn{2}{|c|}{ Band Gap (eV) } \\
\hline & & & & & Calc. & Exp. & Calc. & Exp. \\
\hline \multicolumn{9}{|l|}{$3 d$ metals } \\
\hline $\mathrm{Ti}_{2} \mathrm{O}_{3}$ & $h R 10$ & $R-3 c(167)$ & $R 3 c(161)$ & AFM & 0.9 & & 2.7 & $0.1[42]$ \\
\hline$\alpha-\mathrm{Ti}_{3} \mathrm{O}_{5}$ & $o S 32$ & $\mathrm{Cmcm}$ (63) & $\mathrm{Cm}(8)$ & FiM & 1.0 & & 2.0 & \\
\hline$\beta-\mathrm{Ti}_{3} \mathrm{O}_{5}$ & $m S 32$ & $C 2 / m(12)$ & $\mathrm{Cm}(8)$ & AFM & $0.9,1.0$ & & 1.3 & 0.14 [43] \\
\hline$\gamma-\mathrm{Ti}_{3} \mathrm{O}_{5}$ & $m S 32$ & $I 2 / c(15)$ & $P 1(1)$ & AFM & 1.0 & & 2.3 & \\
\hline$\delta-\mathrm{Ti}_{3} \mathrm{O}_{5}$ & $m S 32$ & $P 2 / a(13)$ & $P-1(2)$ & AFM & 1.0 & & 2.4 & 0.07 [44] \\
\hline$\lambda-\mathrm{Ti}_{3} \mathrm{O}_{5}$ & $m S 32$ & $C 2 / m(12)$ & $\mathrm{Cm}(8)$ & AFM & 1.0 & & 1.7 & \\
\hline $\mathrm{V}_{2} \mathrm{O}_{3}$ & $h R 10$ & $R-3 c(167)$ & $R 3 c(161)$ & $\mathrm{AFM} / \mathrm{AFM}$ & 2.0 & & 3.0 & \\
\hline $\mathrm{V}_{2} \mathrm{O}_{3}$ & $m S 20$ & $I 2 / a(15)$ & $P 2 / c(13)$ & $\mathrm{AFM} / \mathrm{AFM}$ & 2.0 & $1.2[45]$ & 2.8 & 0.6 [46] \\
\hline $\mathrm{VO}_{2}$ & $m P 12$ & $P 2_{1} / c(14)$ & $P 2_{1}(4)$ & $\mathrm{PM} / \mathrm{AFM}$ & 1.1 & & 3.0 & $0.6-0.7[47]$ \\
\hline $\mathrm{VO}_{2}$ & $m S 12$ & $C 2 / m(12)$ & $\mathrm{Cm}(8)$ & $\mathrm{PM} / \mathrm{AFM}$ & 1.1 & & 3.3 & \\
\hline $\mathrm{VO}_{2}$ & $t P 6$ & $\mathrm{P}_{2} / \mathrm{mnm}(136)$ & Cmmm (65) & $\mathrm{PM} / \mathrm{AFM}$ & 1.1 & & 2.8 & - \\
\hline $\mathrm{Cr}_{2} \mathrm{O}_{3}$ & $h R 10$ & $R-3 c(167)$ & $R 3 c(161)$ & $\mathrm{AFM} / \mathrm{AFM}$ & 3.0 & ca. $2.7[48]$ & 5.1 & $3.2-3.4[49,50]$ \\
\hline $\mathrm{CrO}_{2}$ & $t P 6$ & P4/mnm (136) & P4/mnm (136) & FM/FM & 2.4 & $2.01[51]$ & & \\
\hline $\mathrm{MnO}$ & $c F 8$ & $F m-3 m(225)$ & $R-3 m(166)$ & $\mathrm{AFM} / \mathrm{AFM}$ & 4.8 & 4.58 [52] & 3.9 & $3.6-4.2[53,54]$ \\
\hline $\mathrm{MnO}$ & $h P 4$ & $P 6_{3} m c$ (186) & $P m c 2_{1}(26)$ & AFM & 4.8 & & 3.0 & \\
\hline $\mathrm{Mn}_{2} \mathrm{O}_{3}$ & $o P 80$ & $P b c a(61)$ & $P b c a(61)$ & AFM/AFM & $3.9,4.0$ & $2.3-3.9[55,56]$ & 3.0 & 2.17 [57], 2.4 [58] \\
\hline $\mathrm{Mn}_{2} \mathrm{O}_{3}$ & cI80 & $I a-3(206)$ & $I a-3(206)$ & PM/FM & 4.1 & & & \\
\hline $\mathrm{Mn}_{3} \mathrm{O}_{4}$ & $t I 28$ & $I 4_{1} /$ amd $(141)$ & $I 4_{1} /$ amd $(141)$ & FiM/FiM & $3.9,4.0,4.9$ & & 3.2 & $1.77-2.72$ [59] \\
\hline $\mathrm{MnO}_{2}$ & $t I 24$ & $I 4 / m(87)$ & $C 2 / m(12)$ & $\mathrm{AFM} / \mathrm{AFM}$ & 3.1 & & 3.4 & $1.32[60]$ \\
\hline $\mathrm{MnO}_{2}$ & $o P 12$ & Pnam (62) & $P m c 2_{1}(26)$ & AFM/AFM & 3.0 & & 3.5 & $2.57[61]$ \\
\hline $\mathrm{MnO}_{2}$ & $t P 6$ & $\mathrm{P} 4 / \mathrm{mnm}$ (136) & Cmmm (65) & $\mathrm{AFM} / \mathrm{AFM}$ & 3.1 & & 2.1 & $0.3[62]$ \\
\hline $\mathrm{MnO}_{2}$ & $c F 48$ & $F d-3 m(227)$ & $\operatorname{Imma}(74)$ & $\mathrm{AFM} / \mathrm{AFM}$ & 3.1 & 2.78 [63] & 3.7 & $1.7-3.5[64]$ \\
\hline $\mathrm{Fe}_{3} \mathrm{O}_{4}$ & cF56 & $F d-3 m(227)$ & $F d-3 m$ (227) & FiM/FiM & $4.0,4.2$ & $3.82[65]$ & & \\
\hline $\mathrm{Fe}_{3} \mathrm{O}_{4}$ & $m P 56$ & $P 2 / c(13)$ & $P 2 / c(13)$ & FiM/FiM & $3.7-4.3$ & $4.17,4.44[66]$ & 1.6 & 0.14 [11] \\
\hline $\mathrm{Fe}_{2} \mathrm{O}_{3}$ & $h R 10$ & $R-3 c(167)$ & $R-3(148)$ & $\mathrm{AFM} / \mathrm{AFM}$ & 4.2 & $4.6-5.2$ [67] & 4.0 & $5.0[68,69]$ \\
\hline $\mathrm{Fe}_{2} \mathrm{O}_{3}$ & cI80 & Ia-3 (206) & $\mathrm{I} 2{ }_{1} 2_{1} 2_{1}(24)$ & $\mathrm{AFM} / \mathrm{AFM}$ & 4.3 & & 3.3 & $2.2[70]$ \\
\hline $\mathrm{Fe}_{2} \mathrm{O}_{3}$ & $o P 40$ & $\operatorname{Pna2}_{1}$ (33) & $\operatorname{Pna}_{1}$ (33) & FiM/AFM & 4.3 & & 4.2 & $1.6[71]$ \\
\hline $\mathrm{CoO}$ & $c F 8$ & $F m 3 m(225)$ & $R-3 m(166)$ & $\mathrm{AFM} / \mathrm{AFM}$ & 2.7 & $3.35,3.8[72,73]$ & 4.5 & $4.3[74]$ \\
\hline $\mathrm{CoO}$ & $h P 4$ & $P 6_{3} m c$ (186) & $P m c 2_{1}(26)$ & AFM & 2.8 & & 3.2 & \\
\hline $\mathrm{Co}_{3} \mathrm{O}_{4}$ & cF56 & $F d-3 m$ (227) & $F-43 m(216)$ & AFM/AFM & 2.8 & $\begin{array}{c}3.88[75], 3.0[76] \\
1.64[78],\end{array}$ & 4.0 & $0.7[77]$ \\
\hline $\mathrm{NiO}$ & $c F 8$ & $F m 3 m(225)$ & $R-3 m(166)$ & AFM/AFM & 1.7 & $\begin{array}{l}1.77[79], \\
1.90[52]\end{array}$ & 5.2 & $4.0[80], 4.3$ [81] \\
\hline $\mathrm{CuO}$ & $m S 8$ & $C 2 / c(15)$ & $P 2_{1} / c(14)$ & AFM/AFM & 0.6 & $\begin{array}{c}0.65[82], \\
0.68[83,84]\end{array}$ & 3.8 & $1.7[85]$ \\
\hline $\begin{array}{c}\mathrm{Cu}_{4} \mathrm{O}_{3} \\
4 d \text { metals }\end{array}$ & $t I 28$ & $I 4_{1} /$ amd & $\operatorname{Imma}(74)$ & AFM/AFM & 0.7 & $0.66[86]$ & 2.9 & ca. 1.5 [87] \\
\hline $\mathrm{MoO}_{2}$ & $m P 12$ & $P 2{ }_{1} / c(14)$ & $P 2_{1}(4)$ & PM/AFM & 1.1 & & & \\
\hline $\mathrm{TcO}_{2}$ & $m P 12$ & $P 2_{1} / c(14)$ & $P 2_{1}(4)$ & $\mathrm{PM} / \mathrm{AFM}$ & 2.7 & & 2.4 & \\
\hline $\mathrm{RuO}_{2}$ & $t P 6$ & $\mathrm{P} 4 / \mathrm{mnm}(136)$ & Cmmm (65) & $\mathrm{PM} / \mathrm{AFM}$ & 1.5 & $0.05[88]$ & & \\
\hline $\mathrm{RhO}_{2}$ & $t P 6$ & $\mathrm{P4}_{2} / \mathrm{mnm}(136)$ & P4/mnm (136) & $\mathrm{PM} / \mathrm{FM}$ & 0.6 & & & \\
\hline $\mathrm{Ag}_{3} \mathrm{O}_{4}$ & $m P 14$ & $P 2_{1} / c(14)$ & $P 2_{1} / c(14)$ & $\mathrm{PM} / \mathrm{FM}$ & 0.2 & & & \\
\hline \multicolumn{9}{|l|}{$5 d$ metals } \\
\hline $\mathrm{WO}_{2}$ & $m P 12$ & $P 2_{1} / c(14)$ & $P 2_{1}(4)$ & PM/AFM & 0.4 & & & \\
\hline $\mathrm{ReO}_{2}$ & $m P 12$ & $P 2_{1} / c(14)$ & $P 2_{1}(4)$ & $\mathrm{PM} / \mathrm{AFM}$ & 2.1 & & 1.5 & \\
\hline $\mathrm{ReO}_{2}$ & $o P 12$ & Pbcn (60) & $P 2{ }_{1} 2_{1} 2(18)$ & $\mathrm{PM} / \mathrm{AFM}$ & 1.1 & & 1.6 & \\
\hline $\mathrm{ReO}_{2}$ & $t P 6$ & $\mathrm{P}_{2} / \mathrm{mnm}$ (136) & Cmmm (65) & AFM & 2.7 & & 1.6 & \\
\hline $\mathrm{IrO}_{2}$ & $t P 6$ & $\mathrm{P}_{2} / \mathrm{mnm}$ (136) & Cmmm (65) & $\mathrm{PM} / \mathrm{AFM}$ & 0.5 & & & \\
\hline
\end{tabular}

${ }^{a}$ Pearson symbol is used for the description of the crystal structure. It includes the Bravais lattice and the number of atoms in the (nonmagnetic) crystallographic unit cell. ${ }^{b}$ The ground magnetic state determined in this study (FM: ferromagnetic, AFM: antiferromagnetic, and FiM: ferrimagnetic). In the cases where experimental information on the magnetic ground state is available, the first value is the experimentally determined magnetic ground state, and the second one is the ground state determined here (at $0 \mathrm{~K}) .{ }^{c}$ Magnetic moments of the $d$-metal atoms. The calculated values correspond to atomic spin populations. 
The overall performance of the DFT-PBE0/TZVP level of theory in reproducing lattice constants of the magnetic binary $d$-metal oxides is illustrated in Figure 1. In the lattice parameter comparisons for magnetic structures, the nonmagnetic experimental unit cell has been transformed so that it corresponds to the calculated magnetic unit cell. All reported magnetic moments are spin-only values without any orbital contributions, which can lead to some deviations from experimentally determined magnetic moments.

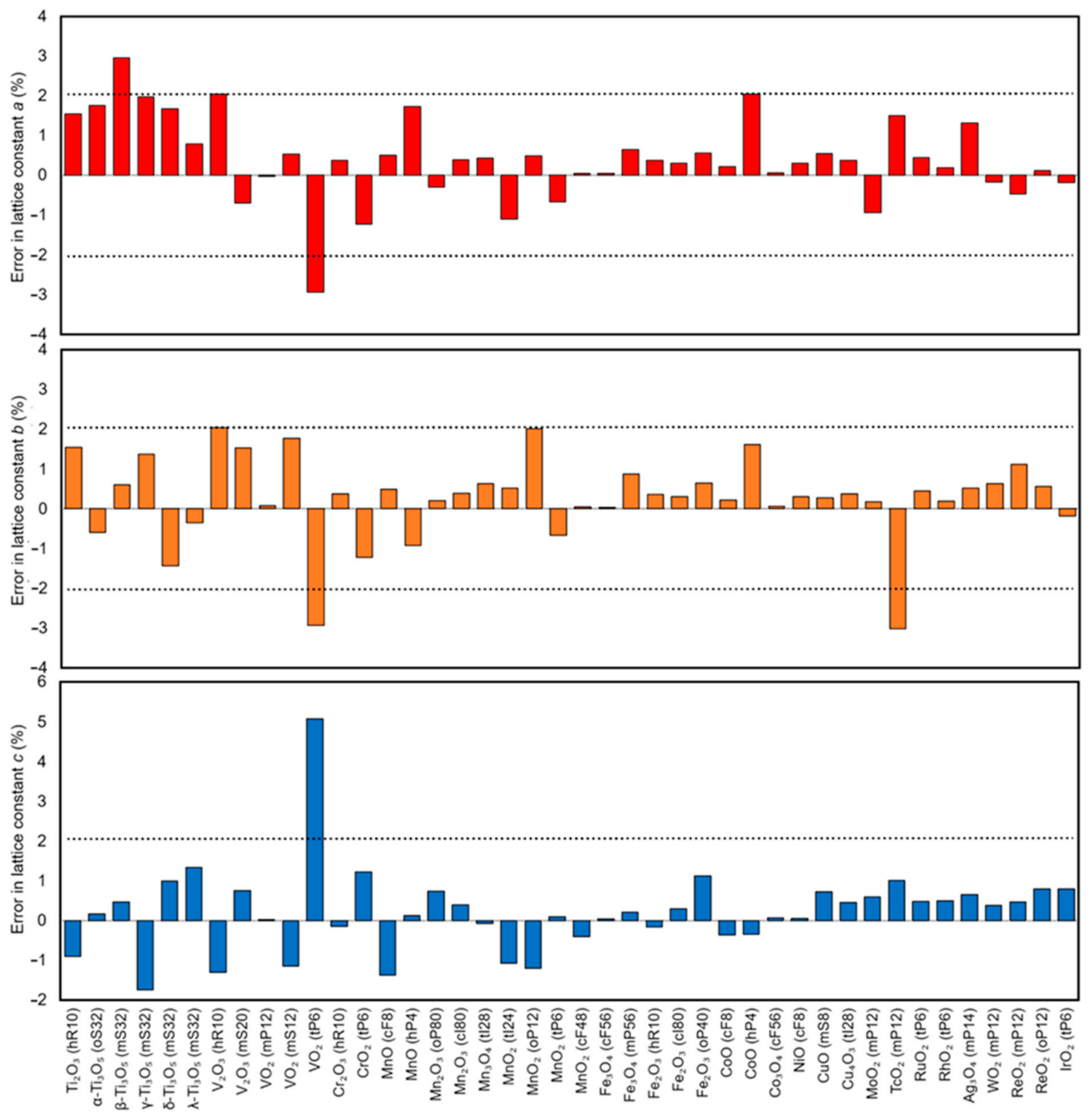

Figure 1. Errors in the optimized DFT-PBE0/TZVP lattice constants in comparison with the experimental lattice constants of the studied magnetic $d$-metal oxides. $\mathrm{ReO}_{2}(t P 6)$ is not included in the plot (see text for details).

Generally, the DFT-PBE0/TZVP level of theory describes the structures of the studied magnetic $d$-metal oxides with good accuracy: mean absolute error (MAE) of the optimized lattice constants is $0.8 \%$, and mean error (ME) is $0.3 \%$. For comparison, using a smaller SVP basis set results in MAE of $0.9 \%$ and ME of $0.1 \%$. The smaller SVP basis set thus appears 
to benefit from some cancellation of errors. For the whole set of the structures, including nonmagnetic $d$-metal oxides, MAE is $1.1 \%$ for TZVP basis set and 1.0\% SVP basis sets, while ME is $0.6 \%$ for TZVP and $0.3 \%$ for SVP. The following metal oxides with abnormally large errors of more than $10 \%$ in the lattice constants are omitted in these statistics as outliers and discussed in the text: $\mathrm{ReO}_{2}(t P 6), \mathrm{HgO}_{2}(m S 6)$, and $\mathrm{HgO}_{2}(o P 12)$.

Out of the magnetic metal oxides investigated here, 16 are described in the literature as antiferromagnets. We were able to find an antiferromagnetic ground state for all of them. The antiferromagnetic configuration was described in the literature in full detail for 12 out of the 16 AFM oxides, and our results reproduced all these reported configurations, except for the helical configuration of $\mathrm{MnO}_{2}(t P 6)$ or $\beta-\mathrm{MnO}_{2}$. Of the four systems that are ferrimagnetic according to the literature, three had the ferrimagnetic lowest-energy configurations, but for one $\left(\mathrm{Fe}_{2} \mathrm{O}_{3}\right.$ oP 40 or $\left.\varepsilon-\mathrm{Fe}_{2} \mathrm{O}_{3}\right)$, we found an antiferromagnetic ground state. Our ground state gives the same magnetic configuration as reported for the ferrimagnet, but the magnetic moments do not have values matching the ferrimagnetic configuration. The one experimentally ferromagnetic oxide $\left(\mathrm{CrO}_{2}\right)$ was also reproduced. Of the 13 paramagnetic systems, our results predict an antiferromagnetic $0 \mathrm{~K}$ configuration for 10 and ferromagnetic for three oxides.

Concerning the predicted band gaps, DFT-PBE0 shows behavior that has been previously discussed in detail in the literature [33]. For systems where the experimental band gap is smaller than $1 \mathrm{eV}$, DFT-PBE0 typically significantly overestimates the band gap. This is evident especially in the case of titanium and vanadium oxides studied here. For band gaps between 2 and $5 \mathrm{eV}$, DFT-PBE0 produces more reasonable estimates. The comparisons of experimental and calculated band gaps are complicated by the fact that material defects such as vacancies can affect the band gap of the oxides significantly. Metal oxides often show, for example, nonstoichiometry, and some oxides such as $\mathrm{TiO}$ were even excluded from the study due to their significant nonstoichiometry. Finally, the band gaps discussed here were obtained simply as the fundamental $0 \mathrm{~K}$ energy gap between the highest occupied and lowest unoccupied bands, and both excitonic and finite temperature effects were neglected. It would, in principle, be possible to improve the agreement with experiments by tuning what is among the exact exchange for each material, but we avoided any empirical parametrization to obtain an overview of the performance of nonempirical PBE0 across the whole d-block.

We first discuss the results for the binary $3 d$ metal oxides, followed by $4 d$ and $5 d$ oxides. Within each period, the $d$-metal oxides are discussed in order from group 3 to group 12 . Additionally, we separately discuss molecular $d$-metal oxides and several mercury oxides.

Some binary $d$-metal oxides were excluded based on the following reasons: $\mathrm{La}_{2} \mathrm{O}_{3}$ (Pearson symbol $h P 5$ ) is a high-T phase stable at $>2303 \mathrm{~K}$ and has occupancy of 0.5 at all sites; $\mathrm{La}_{2} \mathrm{O}_{3}(c I 5)$ has an occupancy of 0.5 for oxygen atoms; $\mathrm{TiO}(m S 20)$ and $\mathrm{TiO}(c F 8)$ are nonstoichiometric; $\mathrm{VO}(c F 8)$ is nonstoichiometric; $\varepsilon-\mathrm{MnO}_{2}(h P 3)$ has 0.5 occupancy on $\mathrm{Mn}$ sites; in the case of $\mathrm{Fe}_{3} \mathrm{O}_{4}(m S 224)$, the reduced structure $\mathrm{Fe}_{3} \mathrm{O}_{4}(m P 56)$ was calculated instead; $\gamma-\mathrm{Fe}_{2} \mathrm{O}_{3}$ (cP56) has occupancy of 0.35 at a Fe site; $\mathrm{MoO}_{3}(m P 16)$ has 0.5 occupancy on several sites; and $\mathrm{TaO}_{2}(t P 6)$ is nonstoichiometric.

\subsection{Magnetic Binary 3D-Metal Oxides}

Six of the studied titanium oxides are magnetic (Figure 2). Ti(III) oxide, $\mathrm{Ti}_{2} \mathrm{O}_{3}(h R 10)$, adopts the trigonal corundum structure with space group $R-3 c$ (no. 167) [89]. Taking the magnetic structure into account changes the space group to subgroup R3c (161) (Figure 2a). There are no experimental data on the magnetic nature of $\mathrm{Ti}_{2} \mathrm{O}_{3}$. We found the AFM configuration to be the ground state of $\mathrm{Ti}_{2} \mathrm{O}_{3}$ with magnetic moments of $0.9 \mu_{B}$, whereas previous calculations by the screened exchange hybrid DFT described $\mathrm{Ti}_{2} \mathrm{O}_{3}$ as a diamagnetic structure [90]. In the same paper, it was mentioned that the ground state of the $\mathrm{Ti}_{2} \mathrm{O}_{3}$ is experimentally determined to be diamagnetic at a low temperature. The lattice parameters of the calculated $\mathrm{Ti}_{2} \mathrm{O}_{3}(h R 10)$ match the experimental values well with a difference of $+1.6 \%$ for $a$ and $-0.9 \%$ for $c$. The calculated band gap of $2.7 \mathrm{eV}$ is clearly overes- 
timated compared to the experimental value of $0.1 \mathrm{eV}$ [42]. However, harmonic frequency calculations performed on the structure revealed imaginary frequencies. Scanning along the imaginary modes reduced the symmetry of the antiferromagnetic structure to space group $C 1 c 1$ (no. 9). This structure was also observed to be energetically more favorable than the higher symmetry one (by about $2 \mathrm{~kJ} / \mathrm{mol}$ per atom), with a band gap of $2.5 \mathrm{eV}$ and magnetic moment of $1.0 \mu_{\mathrm{B}}$.

(a)

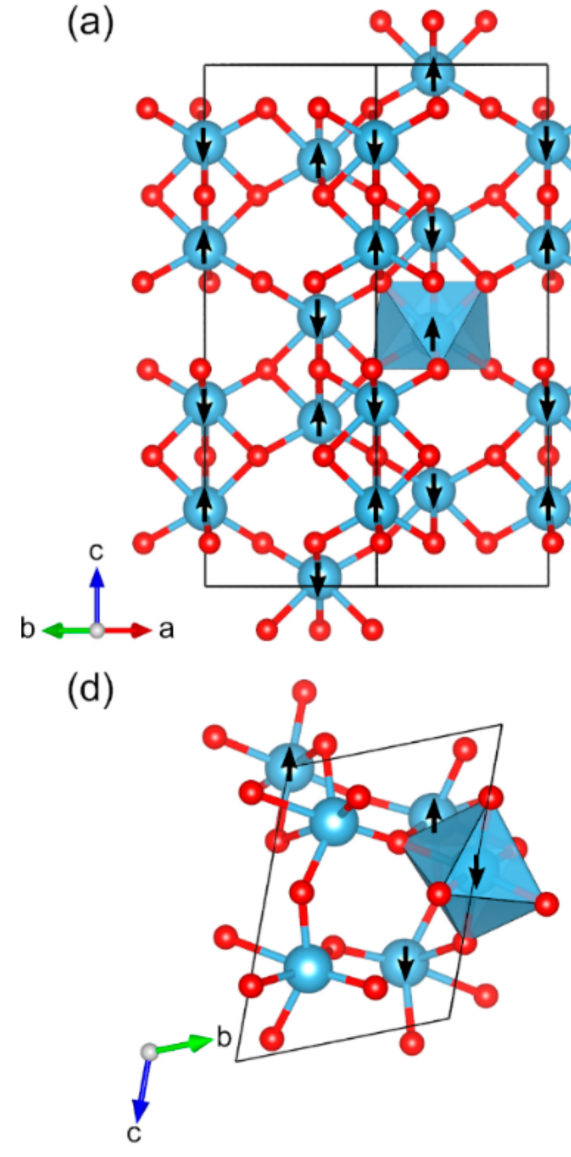

(b)

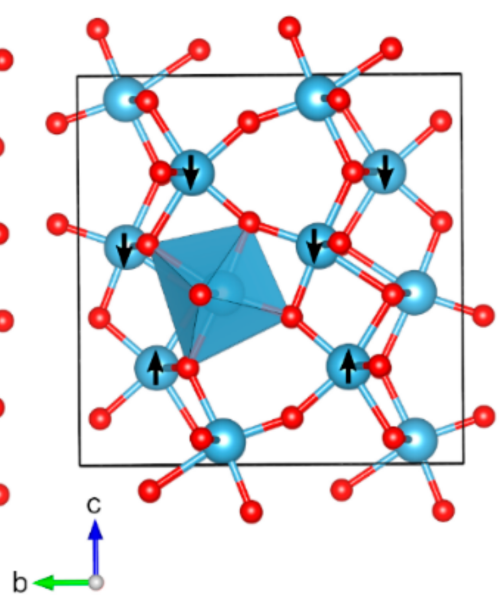

(e)

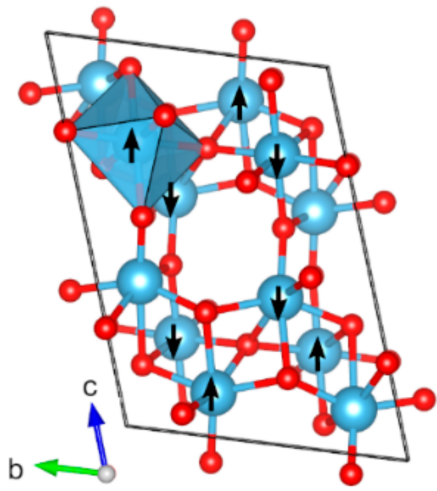

(c)

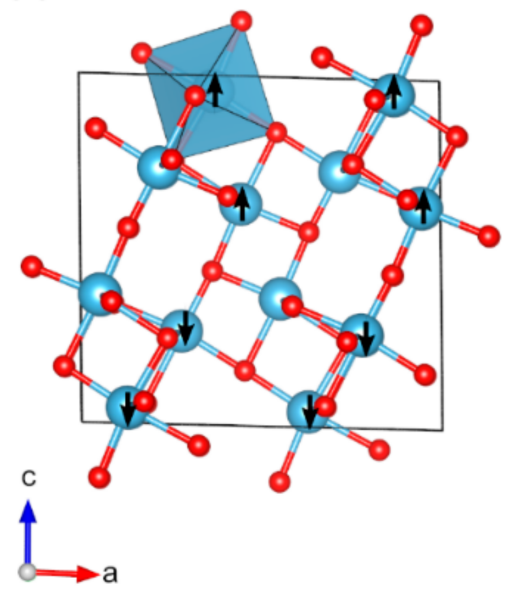

(f)

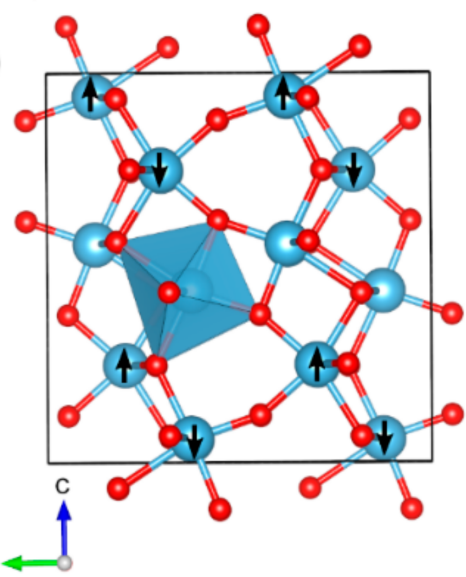

Figure 2. Optimized structures of studied magnetic binary titanium oxides (red: $\mathrm{O}$, blue: Ti): (a) $\mathrm{Ti}_{2} \mathrm{O}_{3}$ (hR10), (b) $\alpha-\mathrm{Ti}_{3} \mathrm{O}_{5}(o S 32)$, (c) $\beta-\mathrm{Ti}_{3} \mathrm{O}_{5}(m S 32),(\mathbf{d}) \gamma-\mathrm{Ti}_{3} \mathrm{O}_{5}(m S 32)$, (e) $\delta-\mathrm{Ti}_{3} \mathrm{O}_{5}(m S 32)$, and (f) $\lambda-\mathrm{Ti}_{3} \mathrm{O}_{5}$ (mS32). The directions of the magnetic moments are illustrated by black arrows. Coordination octahedra of Ti atoms are shown in blue color.

$\mathrm{Ti}\left(\mathrm{III} / \mathrm{IV}\right.$ ) oxide, $\alpha-\mathrm{Ti}_{3} \mathrm{O}_{5}$, (oS32) crystallizes in an orthorhombic crystal structure with space group Cmcm (no. 63) (Figure 2b) [91]. Taking the magnetic ordering into account changes the space group to the subgroup $\mathrm{Cm}$ (8). $\alpha-\mathrm{Ti}_{3} \mathrm{O}_{5}$ exists at temperatures higher than $460 \mathrm{~K}$, while below $460 \mathrm{~K}$ it transforms to $\beta-\mathrm{Ti}_{3} \mathrm{O}_{5}$. There is little experimental data available on the magnetic and electronic properties of $\alpha-\mathrm{Ti}_{3} \mathrm{O}_{5}$. The lattice parameters are described with good accuracy compared to the experiment: the calculated lattice constants differ from the experimental values by $+1.8 \%$ for $a,-0.6 \%$ for $b$, and $+0.2 \%$ for $c$. We identified ferrimagnetic spin-ordering for $\alpha-\mathrm{Ti}_{3} \mathrm{O}_{5}$ with magnetic moments of $1.0 \mu_{\mathrm{B}}$ for some $\mathrm{Ti}^{3+}$ atoms and nonmagnetic $\mathrm{Ti}^{4+}$ (Table 1$)$. The calculated band gaps $(2.0 \mathrm{eV})$ cannot be compared with the literature as there are no previous experimental or computational data, but the material has been reported to be a semiconductor [92].

$\beta-\mathrm{Ti}_{3} \mathrm{O}_{5}(m S 32)$ adopts monoclinic crystal structure with space group $C 2 / m$ (no. 12) [93]. For the magnetic ordering, the space group is changed to the subgroup $\mathrm{Cm}$ (8) (Figure 2c). We found an antiferromagnetic configuration with magnetic moments of 0.9 and $1.0 \mu_{\mathrm{B}}$ 
on $\mathrm{Ti}^{3+}$ atoms to be the most favorable energetically, whereas no experimental data are available on the magnetic ordering. Based on our calculations, $\beta-\mathrm{Ti}_{3} \mathrm{O}_{5}(m S 32)$ is an insulator with a band gap of $1.3 \mathrm{eV}$, compared to experimentally measured $0.14 \mathrm{eV}$ [43]. In comparison to the experiment, the optimized lattice constants of the $\beta-\mathrm{Ti}_{3} \mathrm{O}_{5}(m S 32)$ show differences of $+3.0 \%$ for $a,+0.6 \%$ for $b$, and $+0.5 \%$ for $c$.

Another $\mathrm{Ti}(\mathrm{III} / \mathrm{IV})$ oxide, $\gamma-\mathrm{Ti}_{3} \mathrm{O}_{5}(m S 32)$, has a monoclinic crystal structure with space group $I_{2} / c(15)$ (Figure 2d) [44]. $\gamma-\mathrm{Ti}_{3} \mathrm{O}_{5}$ is formed from $\beta-\mathrm{Ti}_{3} \mathrm{O}_{5}$ at $\sim 250 \mathrm{~K}$ and further transforms to $\delta-\mathrm{Ti}_{3} \mathrm{O}_{5}$ below $237 \mathrm{~K}$ [94]. Based on our calculations, $\gamma-\mathrm{Ti}_{3} \mathrm{O}_{5}$ is an insulator with band gap of $2.3 \mathrm{eV}$, whereas it has been reported to be metallic based on the experimental data [44]. By studying different magnetic configurations, we found that antiferromagnetic $\gamma-\mathrm{Ti}_{3} \mathrm{O}_{5}(m S 32)$ is the most favorable configuration, energetically speaking. The magnetic ground state has four $\mathrm{Ti}^{3+}$ atoms with localized spins and two nonmagnetic $\mathrm{Ti}^{4+}$ atoms (Table 1). In comparison to the experiment, the optimized lattice constants of $\gamma-\mathrm{Ti}_{3} \mathrm{O}_{5}(\mathrm{mS} 32)$ show differences of $+2.0 \%,+1.4 \%$, and $-1.7 \%$ for $a, b$, and $\mathrm{c}$, respectively.

$\delta$ - $\mathrm{Ti}_{3} \mathrm{O}_{5}(m S 32)$ adopts monoclinic crystal structure with space group $P 2 / a$ (no. 13) [44]. The space group of the magnetically ordered structure is P-1 (no. 2) (Figure 2e). Based on our calculations, $\delta-\mathrm{Ti}_{3} \mathrm{O}_{5}(\mathrm{mS} 32)$ is an insulator with a band gap of $2.4 \mathrm{eV}$, and clearly overestimated compared to $0.07 \mathrm{eV}$ from experimental studies [44]. The lattice parameters compare well with experimentally known crystal structure, with differences of $1.7 \%$ for $a$, $-1.4 \%$ for $b$, and $1.0 \%$ for $c$. As for other $\mathrm{Ti}_{3} \mathrm{O}_{5}$ phases, there are no experimental data on magnetic moments of $\delta-\mathrm{Ti}_{3} \mathrm{O}_{5}(m S 32)$, but it is estimated to be $1.0 \mu_{\mathrm{B}}$ for $\mathrm{Ti}^{3+}$ atoms.

Recently, synthesis of a new structure, $\lambda-\mathrm{Ti}_{3} \mathrm{O}_{5}(m S 32)$ was reported that crystallizes in monoclinic crystal structure with space group $C 2 / m$ (no. 12) [43]. We found antiferromagnetic configuration to be the energetically most favorable for $\lambda-\mathrm{Ti}_{3} \mathrm{O}_{5}(m S 32)$, arising from magnetically ordered structure in subgroup Cm (no. 8) (Figure 2f). Calculated magnetic moments are $1.0 \mu_{\mathrm{B}}$ for $\mathrm{Ti}^{3+}$ atoms. Even though experimentally the material was reported to be metallic, our calculations showed band gap of $1.7 \mathrm{eV}$. Such discrepancy may be due to the experimental conditions: a photoreversible metal-semiconductor phase transition. Also, nanoparticles (ca. $25 \mathrm{~nm}$.) were studied and the results can be different compared to single-crystalline bulk material. The optimized lattice constants of $\lambda-\mathrm{Ti}_{3} \mathrm{O}_{5}(m S 32)$ differ from experimental data by $+0.8 \%$ for $a,-0.3 \%$ for $b$, and $1.3 \%$ for $c$.

For vanadium, we investigated five magnetic binary oxides (Figure 3). Two V(III) oxides are known: $\mathrm{V}_{2} \mathrm{O}_{3}(h R 10)$ and $\mathrm{V}_{2} \mathrm{O}_{3}(m S 20) . \mathrm{V}_{2} \mathrm{O}_{3}(h R 10)$ is stable above $155 \mathrm{~K}$ and $\mathrm{V}_{2} \mathrm{O}_{3}$ (mS20) below $155 \mathrm{~K}$ [95]. The $\mathrm{V}_{2} \mathrm{O}_{3}$ ( $\left.h R 10\right)$ modification crystallizes in the trigonal corundum structure with space group $R-3 c$ (no. 167) and has been described in detail in a recent DFT study $[31,69,95-97] . \mathrm{V}_{2} \mathrm{O}_{3}(m S 20)$ has a monoclinic crystal structure with space group $I 2 / a$ (no. 15) [45,98]. In line with experimental data, the magnetic ground state of $\mathrm{V}_{2} \mathrm{O}_{3}(m S 20)$ was found to be AFM configuration with a calculated spin magnetic moment of $2.0 \mu_{\mathrm{B}}$ (exp. value $1.2 \mu_{\mathrm{B}}$ ) (Table 1). The AFM ground state can be realized in the subgroup P2c (no. 13) (Figure 3a). Optimized lattice parameters match the experimental values with good accuracy, lattice parameters differing by $-0.7 \%,+1.5 \%$, and $+0.8 \%$ for $a, b$, and $c$, respectively. The calculated band gap is $2.8 \mathrm{eV}$, while a clearly smaller gap of $0.6 \mathrm{eV}$ has been reported experimentally [46]. 
(a)

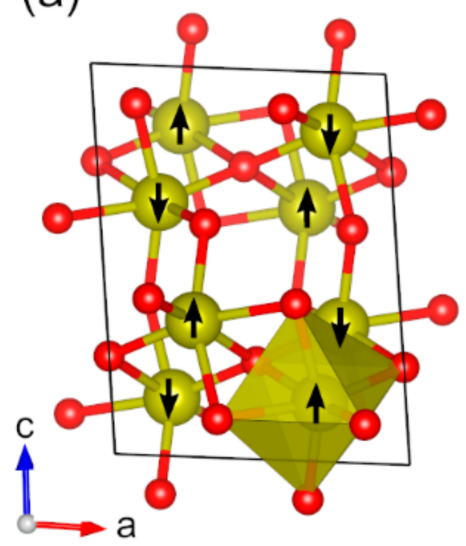

(b)

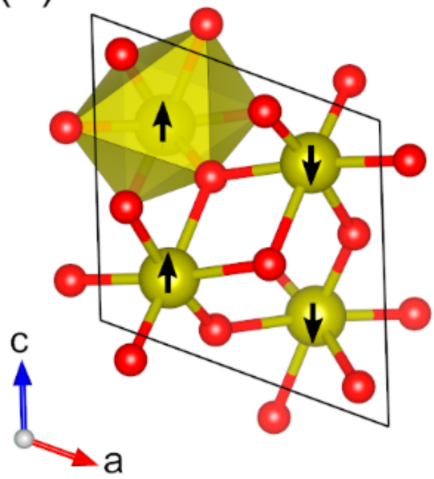

(c)

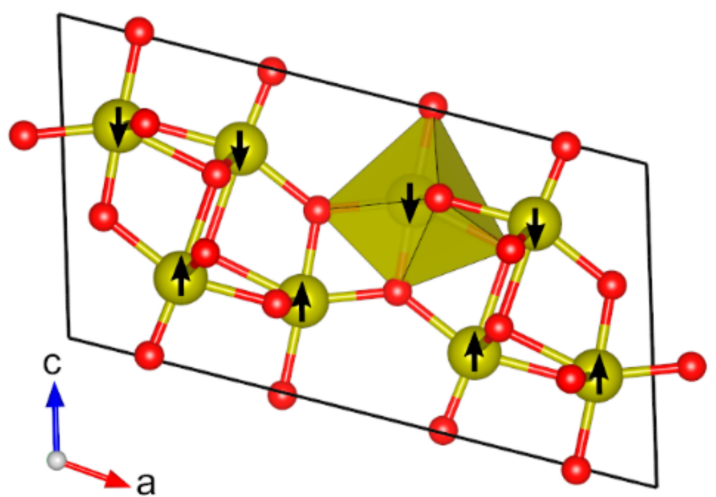

(d)

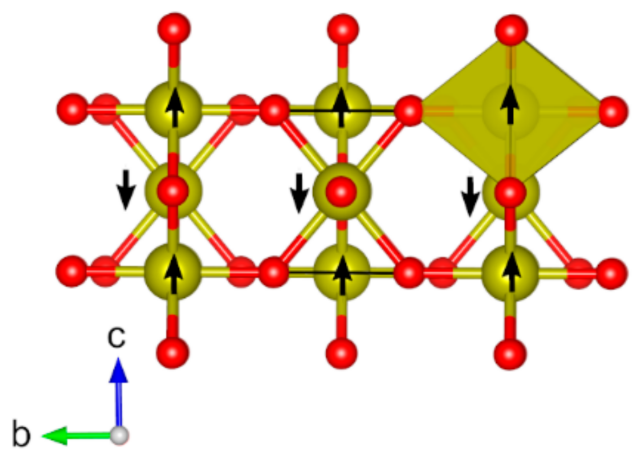

Figure 3. Optimized structures of studied magnetic binary vanadium oxides (red: $\mathrm{O}$, yellow: $\mathrm{V}$ ): (a) $\mathrm{V}_{2} \mathrm{O}_{3}(m S 20),(\mathbf{b}) \mathrm{VO}_{2}(m P 12),(\mathbf{c}) \mathrm{VO}_{2}(m S 12)$, and (d) $\mathrm{VO}_{2}$ (tP6). The directions of magnetic moments are illustrated by black arrows. Coordination octahedra of $\mathrm{V}$ atoms are shown in yellow color.

Three different $\mathrm{VO}_{2}$ modifications are known: $\mathrm{VO}_{2}(m P 12), \mathrm{VO}_{2}(m S 12)$, and $\mathrm{VO}_{2}$ (tP6) $[99,100] . \mathrm{VO}_{2}(m P 12)$ crystallizes in the space group $P 2_{1} / c$ (no. 14), the symmetry being lowered to subgroup $P 2_{1}$ (no. 4) for the magnetically ordered structure (Figure $3 b$ ). $\mathrm{VO}_{2}(m S 12)$ has a monoclinic crystal structure with space group $\mathrm{C} 2 / m$ (no. 12), while taking the magnetic ordering into account lowers the symmetry to subgroup $\mathrm{Cm}$ (no. 8) (Figure 3c). The tetragonal $\mathrm{VO}_{2}(t P 6)$ modification crystallizes in the space group $\mathrm{P}_{2} / \mathrm{mnm}$ (no. 136), and subgroup Cmmm (no. 65) was used to describe the magnetic ordering (Figure 3d).

Overall, all three $\mathrm{VO}_{2}$ modifications have been experimentally characterized to be paramagnetic [101]. $\mathrm{VO}_{2}(m P 12)$ is stable below $340 \mathrm{~K}$, while $\mathrm{VO}_{2}(t P 6)$ is a high-temperature modification that is stable above $340 \mathrm{~K}$. Experimentally, the high-temperature $\mathrm{VO}_{2}(t P 6)$ modification was found to be metallic, whereas our $0 \mathrm{~K}$ calculations show a $2.8 \mathrm{eV}$ band gap [99]. In line with the experimental data, we found $\mathrm{VO}_{2}$ (mP12) to be lower in energy compared to $\mathrm{VO}_{2}(t P 6)$ at $0 \mathrm{~K}$ (by $1.4 \mathrm{~kJ} \mathrm{~mol}^{-1}$ per atom) [102]. The calculated band gap of $\mathrm{VO}_{2}(m P 12)$ is $3.0 \mathrm{eV}$, whereas experimentally it is estimated to be ca. $0.6-0.7 \mathrm{eV}$ (Table 1). $\mathrm{VO}_{2}(m S 12)$ is known to be stable at high pressure and at a zero-strain triple point at $338 \mathrm{~K}$ [103]. The lattice constants differ from experimental values by $0.0 \%,+0.1 \%$, and $0.4 \%$ for $\mathrm{VO}_{2}(m P 12)$ and by $+0.5 \%,+1.8 \%$, and $-1.1 \%$ for $\mathrm{VO}_{2}(m S 12)$. $\mathrm{VO}_{2}(t P 6)$ modification shows relatively large differences of $-2.9 \%$ for $a$ and $\mathrm{b}$ and $5.1 \%$ for $c$ compared to experimental data. This is likely due to the fact the $\mathrm{VO}_{2}(t P 6)$ is a high-temperature modification. Magnetic moments of $\mathrm{VO}_{2}(m P 12)$ were reported in a computational study to be $-1 \mu_{\mathrm{B}}$, which is in line with our calculated value of $1.1 \mu_{\mathrm{B}}$ (Table 1) [104].

In the case of chromium, we investigated two magnetic binary oxides. $\mathrm{Cr}$ (III) oxide, $\mathrm{Cr}_{2} \mathrm{O}_{3}$ (hR10), crystallizes in the corundum structure type with space group $R-3 c$ (no. 167) [48]. $\mathrm{Cr}_{2} \mathrm{O}_{3}$ (hR10) adopts an AFM spin configuration below the Neel temperature 
of $309 \mathrm{~K}$, and the magnetically ordered structure in subgroup $R 3 c$ (no. 161) is identical to $\mathrm{Ti}_{2} \mathrm{O}_{3}(h R 10)$ shown in Figure $2 \mathrm{a}$. The lattice constants of the optimized structure match the experimental data well, with a difference of less than $0.5 \%$. The calculated band gap is $5.1 \mathrm{eV}$, which is larger in comparison with $3.2-3.4 \mathrm{eV}$ from experimental measurements (Table 1). The magnetic moments of the AFM structure are in good agreement with experimental data $\left(3.0 \mu_{\mathrm{B}}\right.$ calc. and $2.7 \mu_{\mathrm{B}}$ exp.).

$\mathrm{Cr}(\mathrm{IV})$ oxide, $\mathrm{CrO}_{2}(t P 6)$, crystallizes in the rutile structure type with space group $\mathrm{P}_{2} / \mathrm{mnm}$ (no. 136) [105]. The magnetic structure is known to be ferromagnetic with a Curie temperature of $386.5 \mathrm{~K}$ (Figure 4), and the material is known to be a metallic conductor [105-108]. The calculated magnetic moment is in good agreement with the experimental value $\left(2.4 \mu_{\mathrm{B}}\right.$ calc. vs. $2.01 \mu_{\mathrm{B}}$ exp.) (Table 1$)$, and the lattice parameters of the optimized structure are in line with experimental data ( $a$ and $c$ differ by $+1.2 \%$ ).

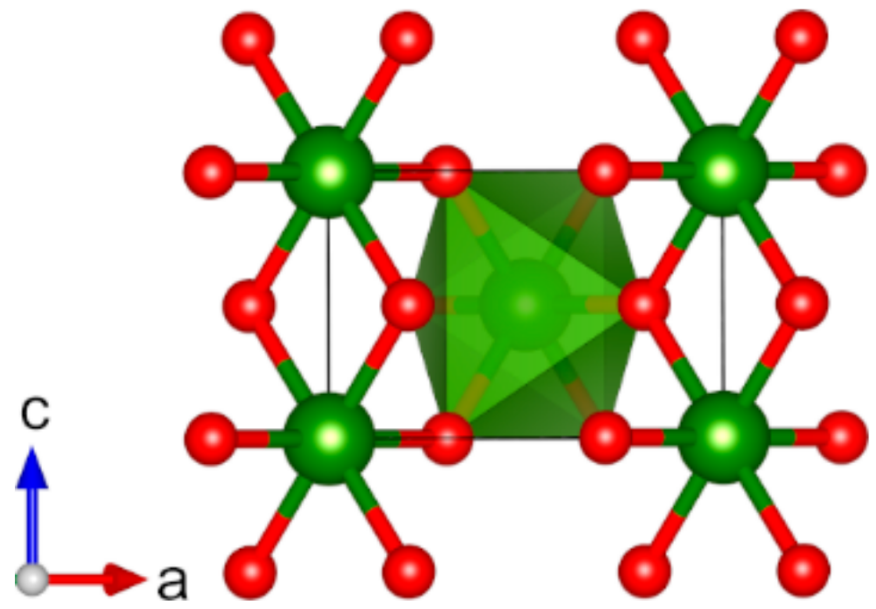

Figure 4. Optimized structure of $\mathrm{CrO}_{2}(t P 6)$ (red: $\mathrm{O}$, green: $\mathrm{Cr}$ ). Spins are aligned along $c$ axis and not visualized. Coordination octahedron of $\mathrm{Cr}$ is shown in green color.

For manganese, we studied nine magnetic binary oxides (Figure 5). Mn(II) oxide, $\mathrm{MnO}(c F 8)$, crystallizes in the rock salt structure type with space group Fm-3m (225). For the magnetically ordered structure, the symmetry is reduced to subgroup $R-3 m$ (no. 166) (Figure 5a) [74]. The magnetic ground state of $\mathrm{MnO}$ is known to be AFM with a Néel temperature of about $122 \mathrm{~K}$ [109]. The lattice parameters of the calculated $\mathrm{MnO}(c F 8)$ structure are in good agreement with experimental data: the difference is $+0.5 \%$ and $-1.4 \%$ for $a$ and $c$, respectively. The calculated magnetic moment, $4.8 \mu_{\mathrm{B}}$, is in line with the experimental value of $4.58 \mu_{\mathrm{B}}$ (Table 1 ), and the calculated band gap is also in the range of experimentally measured band gaps (3.9 eV calc. and 3.6-4.2 eV exp.). Hexagonal polymorph of $\mathrm{MnO}$ crystallizes in the wurtzite structure type with space group $\mathrm{P}_{3} m c$ (186). The magnetic ground state has not been experimentally determined, but previous computational studies report an antiferromagnetic structure $[110,111]$. The space group symmetry of our calculated antiferromagnetically ordered structure is reduced to subgroup $\mathrm{Pmc}_{2}$ (no. 26). The calculated band gap of $3.0 \mathrm{eV}$ is smaller than that of the cubic polymorph, while the magnetic moment is the same at $4.8 \mu_{\mathrm{B}}$. Lattice parameter differences are $+1.7 \%$ for $a,-0.9 \% \%$ for $b$, and $+0.1 \%$ for $c$. 
(a)

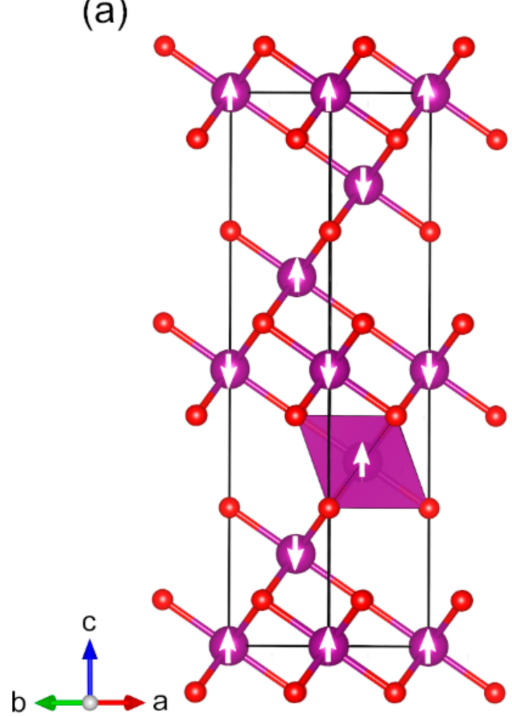

(d)

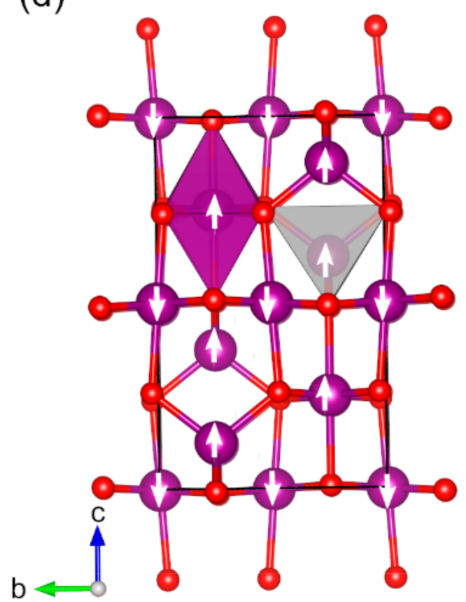

(g)

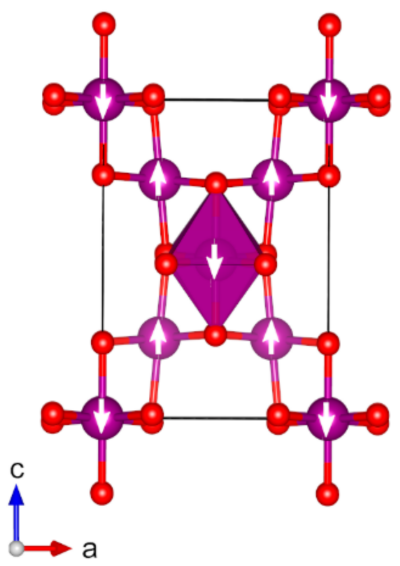

(b)

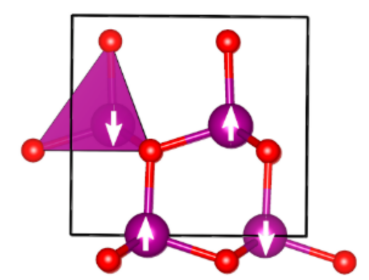

$\mathrm{b} \leftarrow$

(e)

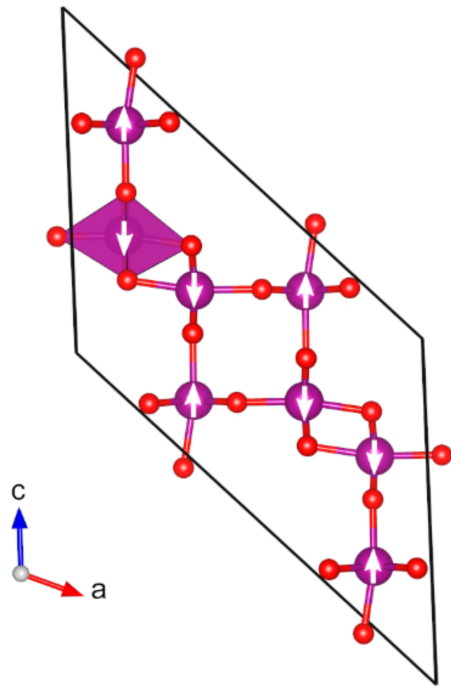

(c)

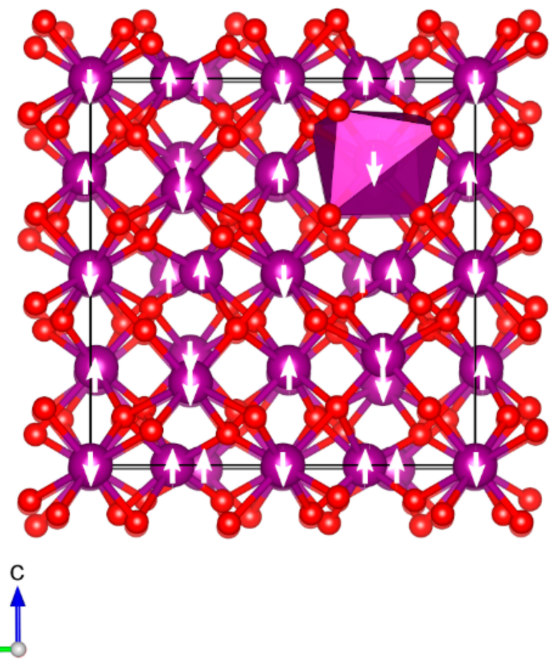

(f)

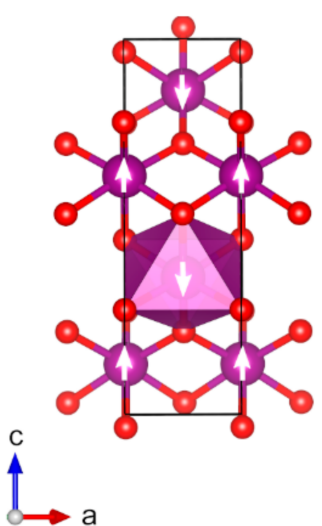

Figure 5. Optimized structures of studied magnetic binary manganese oxides red, $\mathrm{O}$; violet: $\mathrm{Mn}$ : (a) $\mathrm{MnO}$ (cF8), (b) $\mathrm{MnO}$ (hP4), (c) $\mathrm{Mn}_{2} \mathrm{O}_{3}$ (oP80), (d) $\mathrm{Mn}_{3} \mathrm{O}_{4}$ (tI28), (e) $\mathrm{MnO}_{2}$ (tI24), (f) $\mathrm{MnO}_{2}$ $(o P 12)$, and $(\mathrm{g}) \mathrm{MnO}_{2}(c F 48)$. The directions of magnetic moments are illustrated by white arrows. Coordination octahedra and tetrahedra of Mn atoms are shown in violet and light grey colors, respectively. 
Two magnetic $\mathrm{Mn}(\mathrm{III})$ oxides are known: $\mathrm{Mn}_{2} \mathrm{O}_{3}$ (oP80) and $\mathrm{Mn}_{2} \mathrm{O}_{3}$ (cI80) $[112,113]$. The space groups of $\mathrm{Mn}_{2} \mathrm{O}_{3}(o P 80)$ and $\mathrm{Mn}_{2} \mathrm{O}_{3}$ (cI80) are Pbca (no. 61) and Ia-3 (no. 206), respectively. Orthorhombic $\mathrm{Mn}_{2} \mathrm{O}_{3}(o P 80)$ is stable below $302 \mathrm{~K}$, and above this temperature, the cubic $\mathrm{Mn}_{2} \mathrm{O}_{3}$ (cI80) modification becomes more stable. Only $\mathrm{Mn}_{2} \mathrm{O}_{3}$ (oP80) is shown in Figure $5 \mathrm{c}$ as the structures look very similar and only differ by the magnetic ordering. $\mathrm{Mn}_{2} \mathrm{O}_{3}$ (oP80) is experimentally known to be antiferromagnetic, whereas $\mathrm{Mn}_{2} \mathrm{O}_{3}(c I 80)$ is considered to be paramagnetic $[55,56,114]$. Based on our calculations, the $\mathrm{Mn}_{2} \mathrm{O}_{3}$ (cI80) prefers a ferromagnetic spin configuration at $0 \mathrm{~K}$ (Table 1). The lattice parameters are described with good accuracy: the difference between the optimized and experimental lattice constants is less than $0.7 \%$. A direct comparison of the electronic structure of the $\mathrm{Mn}_{2} \mathrm{O}_{3}$ modifications with experiments is not possible due to the absence of experimental data on bulk materials. Band gaps of $\mathrm{Mn}_{2} \mathrm{O}_{3}(o P 80)$ were estimated to be 2.17 and $2.4 \mathrm{eV}$ for nanoparticles and thin films, respectively, whereas our calculated band gap is $3.0 \mathrm{eV}[57,58]$. Based on our calculations, $\mathrm{Mn}_{2} \mathrm{O}_{3}$ (cI80) is a metallic conductor, whereas some experimental studies of nanostructured modifications suggest that the material possesses a band gap $(1.24$ or $1.8 \mathrm{eV})[57,115]$. In this case, however, it is difficult to compare the results as the experimental studies also found that the band gap of $\mathrm{Mn}_{2} \mathrm{O}_{3}$ (cI80) is directly correlated with the size of the nanoparticles (increased size leads to a smaller band gap). Experimentally measured magnetic moments are only available for $\mathrm{Mn}_{2} \mathrm{O}_{3}(o P 80)$, and they have been reported as 2.3-3.9 $\mu_{\mathrm{B}}$ (calculated values are 3.9 and $4.0 \mu_{\mathrm{B}}$ ).

$\mathrm{Mn}(\mathrm{II} / \mathrm{III})$ oxide, $\mathrm{Mn}_{3} \mathrm{O}_{4}(t I 28)$, has a tetragonal crystal structure with space group $I_{1} /$ amd (no. 141) (Table 1) [116]. $\mathrm{Mn}_{3} \mathrm{O}_{4}$ is known to adopt a ferrimagnetic spin configuration at the room temperature, with the magnetically ordered structure having space group Imma (no. 74) (Figure 5d) [117]. The lattice parameters of the optimized structure are larger than the experimental values only by $+0.4 \%,+0.6 \%$, and $-0.1 \%$ for $a, b$, and $c$, respectively. There is no experimental information available on the magnetic moments, but our results are in good agreement with a previously reported computational studies [118,119]. The band gap of $\mathrm{Mn}_{3} \mathrm{O}_{4}$ nanoparticles was found to be in range of 1.77-2.72 eV depending on the size, whereas our calculated bulk band gap is $3.2 \mathrm{eV}$ [59].

For $\mathrm{Mn}(\mathrm{IV})$, we studied four polymorphs: $\mathrm{MnO}_{2}$ (tI24), $\mathrm{MnO}_{2}(o P 12), \mathrm{MnO}_{2}(t P 6)$, and $\mathrm{MnO}_{2}(c F 48)$ [120-123]. $\mathrm{MnO}_{2}(t I 24)$, also known as $\alpha-\mathrm{MnO}_{2}$, crystallizes in space group $I 4 / m$ (no. 87), and for the magnetically ordered structure, the symmetry is lowered to space group $\mathrm{C} 2 / m$ (no. 12) (Figure 5e). $\mathrm{MnO}_{2}(o P 12)$ polymorph $\left(\gamma-/ \mathrm{R}-\mathrm{MnO}_{2}\right)$ adopts an orthorhombic structure with space group Pnam (no. 62), with a magnetically ordered structure in space group $P m c 2_{1}$ (no. 26) (Figure 5f). $\mathrm{MnO}_{2}(t P 6)\left(\beta-\mathrm{MnO}_{2}\right)$ crystallizes in the rutile structure type, space group $\mathrm{P}_{2} / \mathrm{mnm}(136)$, and the magnetic structure in the space group Cmmm (no. 65) (identical to $\mathrm{VO}_{2}(t P 6)$, Figure 3d). $\mathrm{MnO}_{2}(c F 48)\left(\lambda-\mathrm{MnO}_{2}\right)$ crystallizes in the cubic space group $F d-3 m$ (227), whereas the magnetic structure is orthorhombic with space group Imma (no. 74) (Figure 5g). The lattice parameters of the optimized structures match the experimental data very well: the typical difference between calculated and experimental lattice constants is less than $1 \% . \mathrm{MnO}_{2}(t P 6)$ possesses a helical magnetic configuration below $92 \mathrm{~K}[56,124,125]$, whereas all other polymorphs are antiferromagnetic (the Néel temperatures of $\mathrm{MnO}_{2}(t I 24)$ and $\mathrm{MnO}_{2}(c F 48)$ are 24.5 and $32 \mathrm{~K}$, respectively) $[63,126,127]$. The only available experimentally measured magnetic moments are for $\mathrm{MnO}_{2}$ (cF48): $3.1 \mu_{\mathrm{B}}$ calc. compared to $2.78 \mu_{\mathrm{B}}$ exp. (Table 1). The data on band gaps of bulk structures are also very limited, and we only found a gap of $0.3 \mathrm{eV}$ reported for $\mathrm{MnO}_{2}$ (tP6) (2.1 eV calc.). The band gap of thin films of $\mathrm{MnO}_{2}$ (cF48) was estimated from the experiment to be in the range of $1.7-3.5 \mathrm{eV}$, while the calculated band gap for the bulk structure is $3.7 \mathrm{eV}$ [64]. The band gap of nanoflakes of $\mathrm{MnO}_{2}(o P 12)$ was estimated to be $2.57 \mathrm{eV}$, whereas the calculated bulk band gap is $3.5 \mathrm{eV}$ [61].

For iron, we investigated five magnetic binary oxides. Two Fe(II/III) oxides are known: $\mathrm{Fe}_{3} \mathrm{O}_{4}(c F 56)$ and $\mathrm{Fe}_{3} \mathrm{O}_{4}(m P 56)[66,128] . \mathrm{Fe}_{3} \mathrm{O}_{4}(c F 56)$ crystallizes in space group $\mathrm{Fd}-3 m$ (no. 227) (Figure 6a) and $\mathrm{Fe}_{3} \mathrm{O}_{4}(m P 56)$ in space group $P 2 / c$ (no. 13) (Figure 6b). $\mathrm{Fe}_{3} \mathrm{O}_{4}$ $(m P 56)$, which is stable below $125 \mathrm{~K}$, is involved in the Verwey transition below $125 \mathrm{~K}$ from 
the cubic structure [129]. The lattice constants of the optimized $\mathrm{Fe}_{3} \mathrm{O}_{4}(c F 56)$ structure exactly reproduce experimental values, whereas the $\mathrm{Fe}_{3} \mathrm{O}_{4}(m P 56)$ shows differences of $+0.6 \%$, $+0.9 \%$, and $+0.2 \%$ for $a, b$, and $c$, respectively. $\mathrm{Fe}_{3} \mathrm{O}_{4}(c F 56)$ is known to be ferrimagnetic at the room temperature, and it is a metallic conductor $[11,128,130] . \mathrm{Fe}_{3} \mathrm{O}_{4}(m P 56)$ is also a ferrimagnet [66]. Calculated atomic magnetic moments (4.0/4.2 $\mu_{\mathrm{B}}$ for $c F 56$ and 3.7-4.3 $\mu_{\mathrm{B}}$ for $m P 56)$ are in good agreement with the experimental values ( $3.82 \mu_{\mathrm{B}}$ for $c F 56$ and 4.17 and $4.44 \mu_{\mathrm{B}}$ exp. for $\left.m P 56\right)$. The calculated band gap of $\mathrm{Fe}_{3} \mathrm{O}_{4}(m P 56)$ is overestimated by being $1.6 \mathrm{eV}$ in comparison to the experimentally determined $0.1 \mathrm{eV}$ (Table 1 ).
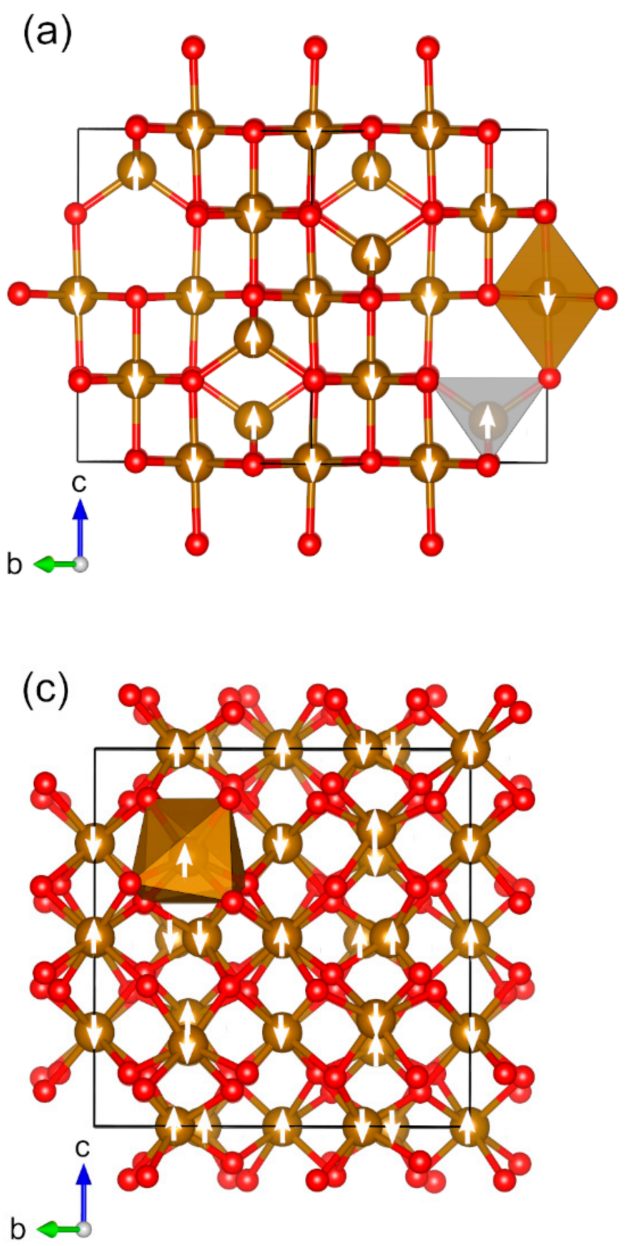

(b)

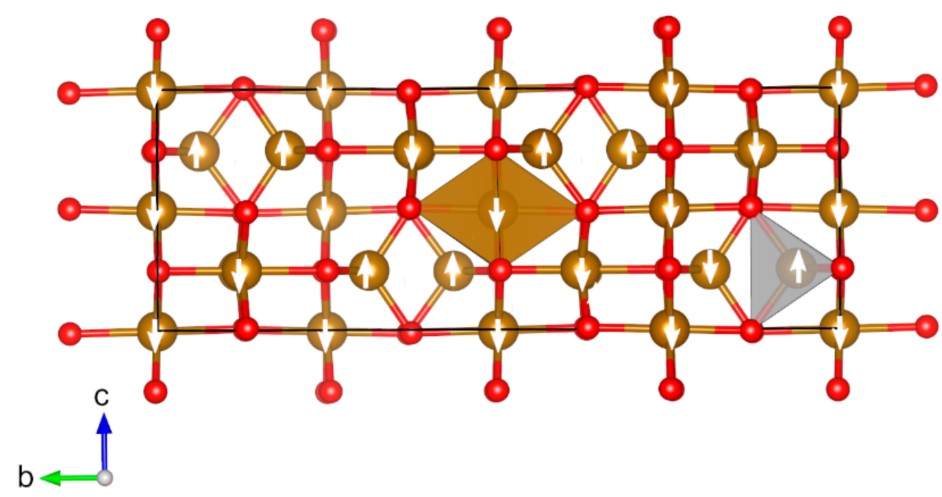

(d)

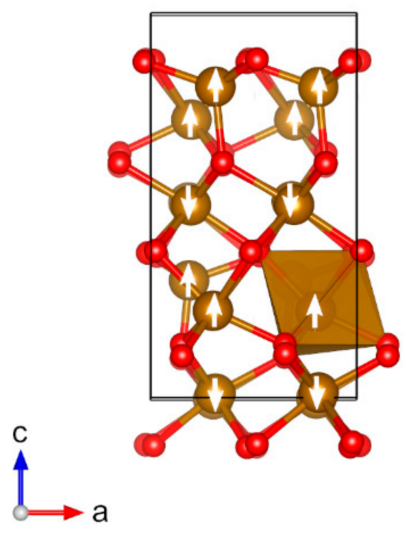

Figure 6. Optimized structures of studied magnetic binary iron oxides (red: $\mathrm{O}$, brown: $\mathrm{Fe}$ ): (a) $\mathrm{Fe}_{3} \mathrm{O}_{4}$ (cF56), (b) $\mathrm{Fe}_{3} \mathrm{O}_{4}$ (mP56), (c) $\mathrm{Fe}_{2} \mathrm{O}_{3}$ (cI80), and (d) $\mathrm{Fe}_{2} \mathrm{O}_{3}$ (oP40). The directions of magnetic moments are illustrated by white arrows. Coordination octahedra and tetrahedra of Fe atoms are shown in brown and light-grey colors, respectively.

We investigated three $\mathrm{Fe}(\mathrm{III})$ oxides: $\mathrm{Fe}_{2} \mathrm{O}_{3}(h R 10), \mathrm{Fe}_{2} \mathrm{O}_{3}(c I 80)$, and $\mathrm{Fe}_{2} \mathrm{O}_{3}(o P 40)[68,131,132]$. The calculated lattice constants are in the good agreement with experimental values, with the largest difference being $0.9 \%$. $\mathrm{Fe}_{2} \mathrm{O}_{3}$ (hR10), hematite or $\alpha-\mathrm{Fe}_{2} \mathrm{O}_{3}$, is known to be antiferromagnetic with the Neel temperature of $955 \mathrm{~K}$, and it has been described in detail in a recent computational study [31]. It crystallizes in the space group $R-3 c$ (no. 167), whereas the symmetry of the magnetically ordered structure is lowered to space group $R-3$ (no. 148). $\mathrm{Fe}_{2} \mathrm{O}_{3}$ (cI80), $\beta-\mathrm{Fe}_{2} \mathrm{O}_{3}$, is also known to be antiferromagnetic $[133,134]$. The space group of the AFM ground state is Ia-3 (no. 206), and the Neel temperature is 119 K (Figure 6c). To our knowledge, there are no experimental data available on the magnetic moments of $\mathrm{Fe}_{2} \mathrm{O}_{3}$ (cI80). The calculated band gap is overestimated to be $3.3 \mathrm{eV}$ compared to the experimental value of $2.2 \mathrm{eV}$ (Table 1). $\mathrm{Fe}_{2} \mathrm{O}_{3}(o P 40), \varepsilon-\mathrm{Fe}_{2} \mathrm{O}_{3}$, is ferrimagnetic with a Curie 
temperature of $495 \mathrm{~K}$ [135]. However, we found the antiferromagnetic configuration to be the energetically most favorable configuration (ferromagnetic configurations were $2.6-4.7 \mathrm{~kJ}$ $\mathrm{mol}^{-1}$ per atom higher in energy, see Supplementary Materials). Spins are correctly aligned in the structure, but Fe atoms in the tetrahedral sites have smaller magnetic moments than they would in a ferrimagnetic configuration. The space group of $\mathrm{Fe}_{2} \mathrm{O}_{3}(o P 40)$ is $P n a 2_{1}$ (no. 33), and the magnetically ordered structure has the same space group (Figure $6 \mathrm{~d}$ ). The calculated band gap is estimated to be $4.2 \mathrm{eV}$, which is clearly overestimated in comparison to the experimental value being $1.6 \mathrm{eV}$. A comparison of estimated magnetic moments is not feasible as values are only available for nanoparticles.

$\mathrm{Co}(\mathrm{II})$ oxide, $\mathrm{CoO}(c F 8)$, crystallizes in the rocksalt structure with space group Fm-3m (no. 225) [72-74]. Similar to $\mathrm{MnO}(c F 8)$, the space group of the magnetically ordered structure is $R-3 m$ (no. 166). CoO $(c F 8)$ is described in detail in recent computational studies [31,136]. The hexagonal wurtzite polymorph of $\mathrm{CoO}, \mathrm{P} 63 m c$ (no. 186), has an antiferromagnetic structure similar to hexagonal $\mathrm{MnO}$ [137], with the magnetical ordering lowering the space group to $P m c 2_{1}$ (no. 26). The calculated band gap is $3.2 \mathrm{eV}$, which is smaller than the value of $4.5 \mathrm{eV}$ of the cubic polymorph. The magnetic moment is $2.8 \mu_{\mathrm{B}}$. The lattice parameter differences compared to experiments are $+2.0 \%$ for $a,+1.6 \%$ for $b$, and $-0.3 \%$ for $c$. $\mathrm{Co}(\mathrm{II} / \mathrm{III})$ oxide. $\mathrm{Co}_{3} \mathrm{O}_{4}(c F 56)$ has a cubic structure with space group Fd-3m (no. 227) [138]. The magnetic structure is antiferromagnetic with space group F-43m (no. 216) and shows a Neel temperature of $30 \mathrm{~K}$ (Figure 7) [75]. The lattice constants are almost identical to the experimental values with a difference of only $0.1 \%$. The calculated magnetic moments of $\mathrm{Co}^{2+}, 2.8 \mu_{\mathrm{B}}$, reproduce at least one reported experimental value of $3.0 \mu_{\mathrm{B}}$ (Table 1). The reports on $\mathrm{Co}_{3} \mathrm{O}_{4}$ band gap show a large variation from 0.74 even up to $4.4 \mathrm{eV}$, with the most recent studies suggesting a fundamental gap of about $0.8 \mathrm{eV}[13,77]$. Our calculated band gap of $4.0 \mathrm{eV}$ is clearly overestimated in comparison to the values of less than the $1 \mathrm{eV}$ suggested in recent studies. Singh et al. have shown that the electronic and magnetic properties of $\mathrm{Co}_{3} \mathrm{O}_{4}$ are very sensitive to the choice of the Hubbard parameter (for PBE $+U_{e f f}$ ) and the amount of exact exchange included in the HSE06 hybrid functional [13]. Other computational studies have also shown that the DFT $+U$ calculations with $U$ values calibrated to the experimental data are required to obtain a good agreement with experimental band gaps $[139,140] . \mathrm{Co}_{3} \mathrm{O}_{4}$ appears to be a very good benchmark case for any new nonempirical DFT methods.

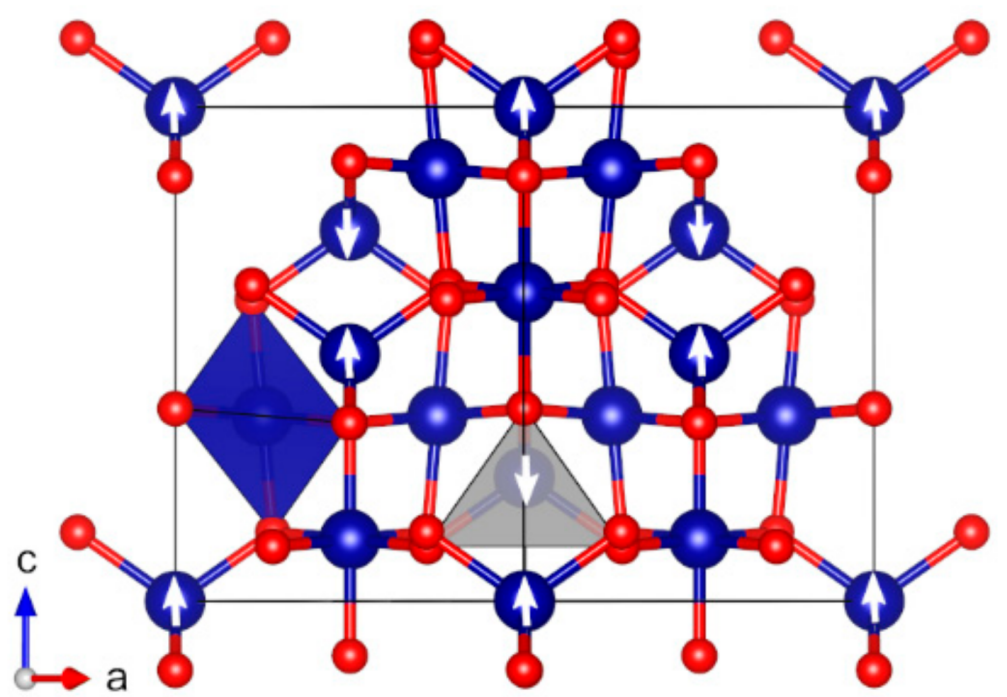

Figure 7. Optimized structure of $\mathrm{Co}_{3} \mathrm{O}_{4}(c F 56)$ (red: $\mathrm{O}$, dark blue: $\mathrm{Co}$ ). The directions of magnetic moments are illustrated by white arrows. Coordination octahedra and tetrahedra of Co atoms are shown in dark-blue and light-grey colors, respectively. 
Nickel(II) oxide, $\mathrm{NiO}(c F 8)$, crystallizes in the rocksalt structure, and it has a similar antiferromagnetic structure as $\mathrm{MnO}(c F 8)$ and $\mathrm{CoO}(c F 8)[52,74,141,142]$. $\mathrm{NiO}(c F 8)$ is described in detail in recent computational studies [31,136].

Copper(II) oxide, $\mathrm{CuO}(m S 8)$, is known to have a monoclinic structure with space group C2/c (no. 15) and antiferromagnetic ground state [82-84,143,144]. The space group of the magnetic structure is $P 2_{1} / c$ (no. 14), and the structure is described in detail in previous computational studies $[31,35]$. Copper(I/II) oxide, $\mathrm{Cu}_{4} \mathrm{O}_{3}(t / 28)$, crystallizes in a tetragonal crystal structure with space group $I 4_{1} /$ amd (no. 141), with the symmetry of the magnetic structure being reduced to the subgroup Imma (no. 74) (Figure 8) [145,146]. $\mathrm{Cu}_{4} \mathrm{O}_{3}$ $(t I 28)$ is known to be stable as an antiferromagnetic structure with the Neel temperature of $41 \mathrm{~K}$ [86]. Whereas the band gap of the optimized structure is overestimated compared with experimentally estimated $(2.9 \mathrm{eV}$. calc. vs. $-1.5 \mathrm{eV}$. exp.), the calculated magnetic moments of $\mathrm{Cu}^{2+}\left(0.7 \mu_{\mathrm{B}}\right)$ are almost identical to experimental value of $0.66 \mu_{\mathrm{B}}$. The lattice parameters of the optimized structure also match the experimental data well, with differences of less than $0.5 \%$

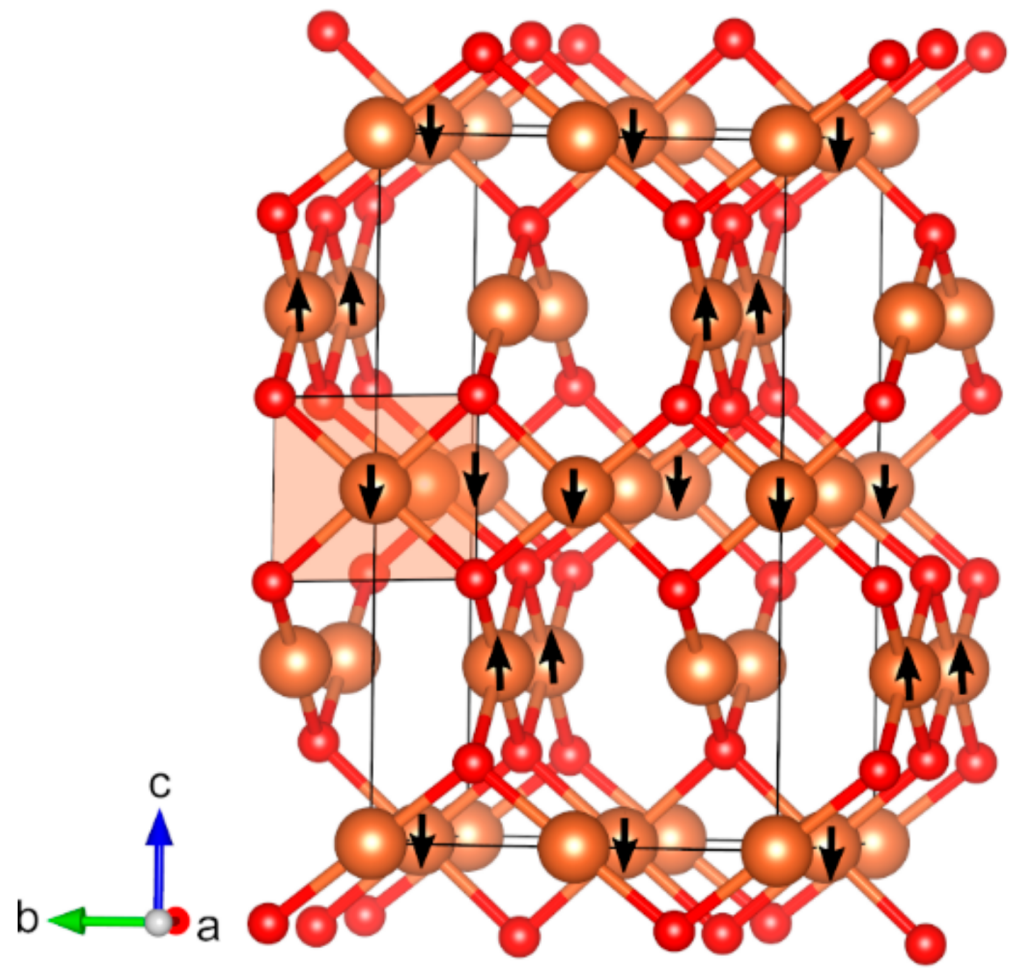

Figure 8. Optimized structure of $\mathrm{Cu}_{4} \mathrm{O}_{3}$ (tI28) (red: $\mathrm{O}$, light brown: $\mathrm{Cu}$ ). The directions of magnetic moments are illustrated by black arrows. Coordination square planar of $\mathrm{Cu}$ atoms that are shown is a light-brown color.

\subsection{Magnetic Binary 4D-Metal Oxides}

$\mathrm{Mo}(\mathrm{IV})$ oxide, $\mathrm{MoO}_{2}(\mathrm{mP12})$, crystallizes in a monoclinic crystal structure with space group $P 2_{1} / c$ (no. 14) [147]. It has been determined to be paramagnetic at room temperature $[148,149]$. We found an antiferromagnetic configuration to possess the lowest energy at $0 \mathrm{~K}$ for $\mathrm{MoO}_{2}(m P 12)$ (identical to $\mathrm{VO}_{2}(m P 12)$ and shown in Figure $\left.3 b\right)$. Therefore, the symmetry of the magnetic configuration is reduced to subgroup $P 2_{1}$ (no. 4$) . \mathrm{MoO}_{2}(m P 12)$ is a metallic conductor [148]. The lattice parameters of the optimized $\mathrm{MoO}_{2}(\mathrm{mP12})$ are in good agreement with the experimental data, with the differences $<1 \%$. Estimated magnetic moments of Mo atoms are $1.1 \mu_{\mathrm{B}}$.

For radioactive $\mathrm{Tc}$, a magnetic $\mathrm{Tc}(\mathrm{IV})$ oxide is known. $\mathrm{TcO}_{2}(m P 12)$ is isostructural to $\mathrm{MoO}_{2}$ ( $m P 12$ ) with $P 2 / c$ space group (no. 12) and subgroup $P 2_{1}$ (no. 4 ) for the magnetic configuration (identical to $\mathrm{VO}_{2}(m P 12)$, Figure 3b) [150]. Overall, very few data on the $\mathrm{TcO}_{2}$ 
(mP12) are available. We found an antiferromagnetic ground state with magnetic moments of $2.7 \mu_{\mathrm{B}}$ on the metal atoms. Based on our results, $\mathrm{TcO}_{2}(m P 12)$ possesses a band gap of $2.4 \mathrm{eV}$. Compared to the experimental crystal structure, the lattice parameters $a, b$, and $c$ differ by $+1.5 \%,-3.0 \%$, and 1.0 , respectively.

$\mathrm{Ru}(\mathrm{IV})$ oxide, $\mathrm{RuO}_{2}(t P 6)$, is a rutile structure with space group $P 4_{2} / m n m$ (no. 136) [151]. The symmetry of the magnetically ordered structure is lowered to subgroup Cmmm (no. 65) (identical to $\mathrm{VO}_{2}(m P 12)$, Figure $\left.3 \mathrm{~d}\right)$. It was originally determined to be paramagnetic within 4-300 K [152], but based on recent experimental and computational work, it is an antiferromagnet with a Neel temperature over $300 \mathrm{~K}$ [88]. We found an antiferromagnetic ground state with magnetic moment of $1.5 \mu_{\mathrm{B}}$, whereas the experiments showed small magnetic moments of $0.05 \mu_{\mathrm{B}}$. The lattice parameters of the optimized structure are in good agreement with the experimental data (with differences less than $0.5 \%$ ).

$\mathrm{Rh}(\mathrm{IV})$ oxide, $\mathrm{RhO}_{2}(\mathrm{tP} 6)$, also adopts the rutile structure with space group $\mathrm{P} 4_{2} / \mathrm{mnm}$ (no. 136) [153]. We found a ferromagnetic ground state (identical to $\mathrm{CrO}_{2}$, Figure 4). Based on our calculations, $\mathrm{RhO}_{2}$ is metallic (Table 1) [154]. The experimental data on electronic and magnetic properties are limited, and it has only been mentioned that $\mathrm{RhO}_{2}(t P 6)$ should be paramagnetic at room temperature [155]. The structural properties are in good agreement with the experimental data: the lattice parameters differ by $+0.2 \%$ and $+0.5 \%$ for $a$ and $c$, respectively.

$\mathrm{Ag}(\mathrm{II} / \mathrm{III})$ oxide, $\mathrm{Ag}_{3} \mathrm{O}_{4}(m P 14)$, crystallizes in a monoclinic crystal structure with space group $P 2{ }_{1} / c$ (no. 14) (Figure 9) [156]. The lattice parameters match the experimental data well: the differences between the optimized and experimental lattice constants are $+1.2 \%$, $+0.5 \%$, and $+0.6 \%$ for $a, b$, and $c$, respectively. $\mathrm{Ag}_{3} \mathrm{O}_{4}$ has been reported to be paramagnetic above $70 \mathrm{~K}[156,157]$. At $0 \mathrm{~K}$, we found the ferromagnetic ground state with $\mathrm{Ag}^{3+}$ magnetic moments of $0.2 \mu_{\mathrm{B}}$. We found $\mathrm{Ag}_{3} \mathrm{O}_{4}$ to be the metallic conductor (Table 1). The electronic structure of $\mathrm{Ag}_{3} \mathrm{O}_{4}$ has been described as magnetic in the literature [158], but no further details on how it was determined or other experimental data were provided.

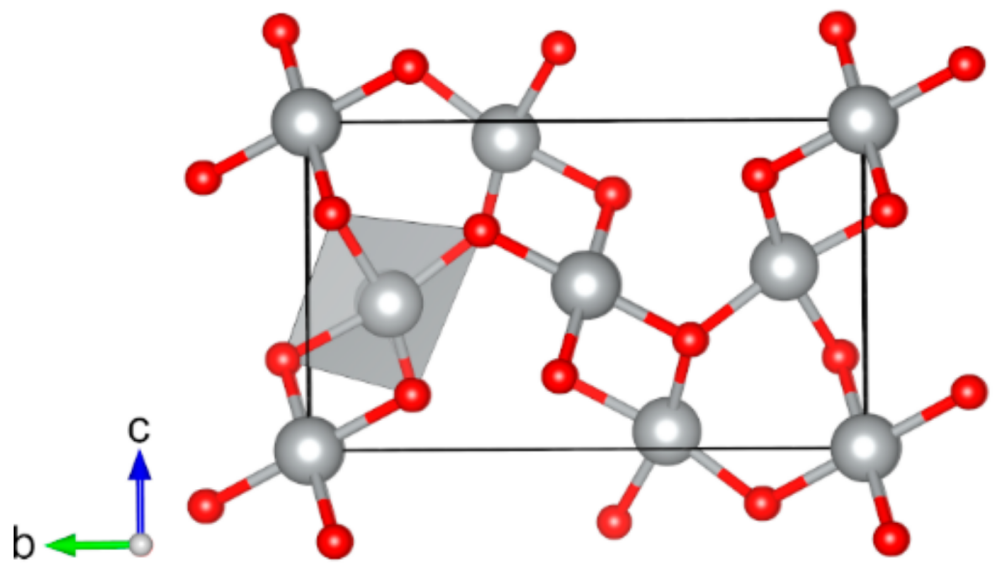

Figure 9. Optimized structure of $\mathrm{Ag}_{3} \mathrm{O}_{4}(m P 14)$ (red: $\mathrm{O}$, light grey: Ag). Spins are aligned up along $c$ axis and not visualized. Square planar coordination of $\mathrm{Ag}$ atoms is shown in a light-grey color.

\subsection{Magnetic Binary 5D-Metal Oxides}

$\mathrm{W}(\mathrm{IV})$ oxide, $\mathrm{WO}_{2}(\mathrm{mP12})$, has a monoclinic crystal structure with space group $P 2_{1} / c$ (no. 14) [159]. The magnetically ordered structure has a lower symmetry with subgroup $P 2{ }_{1}$ (no. 4) (identical to $\mathrm{VO}_{2}(m P 12)$, Figure $\left.3 b\right)$. To our knowledge, there are no experimental or computational studies on the magnetic properties of $\mathrm{WO}_{2}(m P 12)$. The paramagnetic ground state is mentioned in the book by Richards [155], which describes $\mathrm{WO}_{2}$ as a metallic compound. However, the experimental conditions of the measurements are not provided. Based on our calculations, the ground state of $\mathrm{WO}_{2}(\mathrm{mP} 12)$ is antiferromagnetic with magnetic moments of $0.4 \mu_{\mathrm{B}}$. The lattice parameters of the calculated structure are in good 
agreement with the experimental data, showing differences of $-0.2 \%$ for $a,+0.6 \%$ for $b$, and $+0.4 \%$ for $c$.

For rhenium, we investigated three $\mathrm{Re}(\mathrm{IV})$ magnetic oxides: $\mathrm{ReO}_{2}(m P 12), \mathrm{ReO}_{2}(o P 12)$, and $\mathrm{ReO}_{2}(t P 6)$. $\mathrm{ReO}_{2}(m P 12)$ crystallizes in a monoclinic crystal structure with space group $P 2_{1} / c$ (no. 14). For the magnetically ordered structure, the symmetry is lowered to subgroup $P 2_{1}$ (no. 4) (identical to $\mathrm{VO}_{2}(m P 12)$ and shown in Figure 3b). Monoclinic $\mathrm{ReO}_{2}(m P 12)$ structure is experimentally characterized to be paramagnetic below $573 \mathrm{~K}[160,161] . \operatorname{ReO}_{2}$ (oP12) crystallizes in an orthorhombic crystal structure with space group Pbcn (no. 60) [162]. The symmetry of the magnetically ordered structure is lowered to space group $P 2{ }_{1} 2{ }_{1} 2$ (no. 18) (Figure 10). It has been determined to be a metallic and paramagnetic compound between $4.2 \mathrm{~K}$ and the room temperature [148]. Based on our calculations at $0 \mathrm{~K}, \mathrm{ReO}_{2}$ $(o P 12)$ has a band gap of $1.6 \mathrm{eV}$. We found an antiferromagnetic ground state with magnetic moments of $1.1 \mu_{\mathrm{B}}$. In agreement with our findings, a recent computational study showed that at $0 \mathrm{~K}$, the structure adopts antiferromagnetic ordering [163]. $\mathrm{ReO}_{2}$ (tP6) adopts tetragonal crystal structure with space group $P 4_{2} / m n m$ (no. 136) $[162,164,165]$. The symmetry of the magnetically ordered structure is lowered to subgroup $\mathrm{Cmmm}$ (no. 65) (identical to $\mathrm{VO}_{2}$ $(t P 6)$, Figure 3d). The lattice parameters of the optimized $\mathrm{ReO}_{2}(m P 12)$ and $\mathrm{ReO}_{2}(o P 12)$ structures are in good agreement with experimental data, showing differences of less than $1.1 \%$. However, $\mathrm{ReO}_{2}(t P 6)$ shows a difference of about $14 \%$ for the lattice constant $c$. Similar to tetragonal $\mathrm{VO}_{2}$, it is possible that tetragonal $\mathrm{ReO}_{2}(t P 6)$ structure at $0 \mathrm{~K}$ is different from the experimental structure determined at a higher temperature (the material was synthesized at $693 \mathrm{~K})$. Very limited information is available on tetragonal $\mathrm{ReO}_{2}(t P 6)$; only one experimental/computational paper has been reported [166]. DFT-LDA $+U$ calculations suggested that the $\mathrm{ReO}_{2}(t P 6)$ structure is antiferromagnetic with magnetic moments of $1.0 \mu_{\mathrm{B}}$ on Re atoms. Based on our calculations, the magnetic moment on Re atoms is $2.1 \mu_{\mathrm{B}}$ and the band gap is $1.5 \mathrm{eV}$.

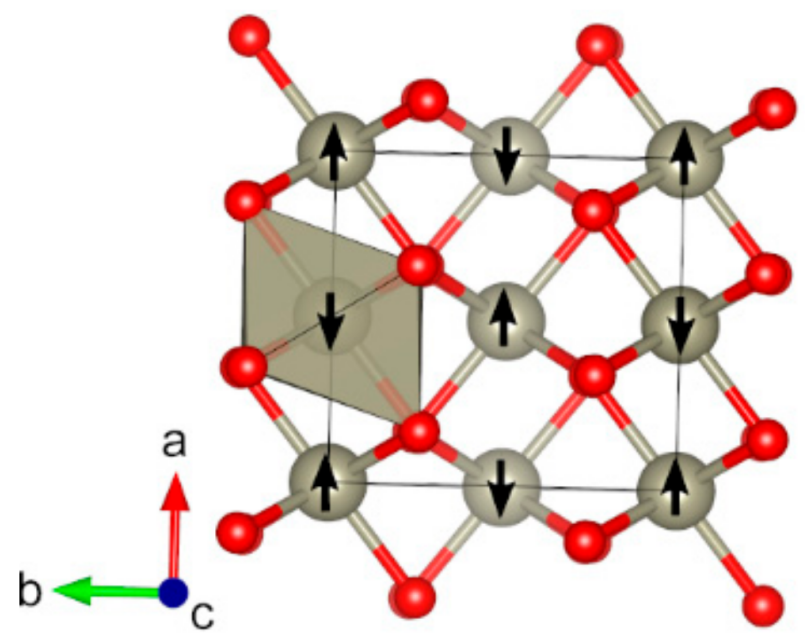

Figure 10. Optimized structure of $\mathrm{ReO}_{2}$ (mP12) (red: $\mathrm{O}$, grey: Re). The directions of magnetic moments are illustrated by black arrows. Coordination octahedra of Re atoms is shown in grey color.

$\mathrm{Ir}(\mathrm{IV})$ oxide $\mathrm{IrO}_{2}$ crystallizes in a tetragonal crystal structure with space group $P 4_{2} / \mathrm{mnm}$ (no. 136) [167]. $\mathrm{IrO}_{2}(t P 6)$ is considered to be paramagnetic in the temperature range of $4.2-300 \mathrm{~K}$, and we found an antiferromagnetic spin configuration to be energetically the most favorable at $0 \mathrm{~K}$ [152]. The magnetic moments are $0.5 \mu_{\mathrm{B}}$. The symmetry of the magnetically ordered structure is lowered to subgroup Cmmm (no. 65), identically to $\mathrm{VO}_{2}(t P 6)$ (Figure $3 \mathrm{~d}$ ). The lattice parameters of the calculated structure differ from the experimental data by $-0.2 \%$ for $a, b$, and $+0.8 \%$ for $c$. $\mathrm{IrO}_{2}$ is a metallic conductor [168]. 


\subsection{D-Metal Oxides with Molecular Structures}

Some binary $d$-metal oxides exist as molecular crystals, where molecular units are held together by weak intermolecular interactions (van der Waals forces): $\mathrm{CrO}_{3}$ (oS16), $\mathrm{MoO}_{3}(o P 16), \mathrm{WO}_{3}(t P 8), \mathrm{Mn}_{2} \mathrm{O}_{7}(m P 72), \mathrm{Tc}_{2} \mathrm{O}_{7}$ (oP36), $\mathrm{RuO}_{4}(c P 40), \mathrm{RuO}_{4}(m S 20)$, and $\mathrm{OsO}_{4}(m S 20)$. Even though the studied molecular crystals are nonmagnetic, they represent interesting cases because the weak intermolecular interactions are not described properly by standard DFT methods such as PBE or PBE0 $[169,170]$. Table 2 shows a summary of the optimized lattice parameters for the binary $d$-metal oxides with molecular crystal structures.

Table 2. Optimized lattice parameters of binary $d$-metal oxides with molecular crystal structures, obtained at the DFT-PBE0/TZVP and DFT-PBE0-D3/TZVP levels of theory. Errors with respect to experimental lattice parameters are shown in parentheses.

\begin{tabular}{|c|c|c|c|c|c|c|c|c|c|c|c|}
\hline \multirow{2}{*}{ Oxide } & \multirow{2}{*}{$\begin{array}{l}\text { Pearson } \\
\text { Symbol }\end{array}$} & \multirow{2}{*}{$\begin{array}{l}\text { Space } \\
\text { Group }\end{array}$} & \multicolumn{3}{|c|}{$a(\AA)$} & \multicolumn{3}{|c|}{$b(\AA)$} & \multicolumn{3}{|c|}{$c(\AA)$} \\
\hline & & & No D3 & $\underset{\mathrm{a}}{\mathrm{D} 3 \mathrm{ZD}}$ & $\underset{\text { b }}{\text { D3 BJ }}$ & No D3 & D3 ZD & D3 BJ & No D3 & D3 ZD & D3 BJ \\
\hline $\mathrm{CrO}_{3}[171]$ & $o S 16$ & $\begin{array}{c}\mathrm{C} 2 \mathrm{~cm} \\
(40)\end{array}$ & $\begin{array}{l}5.748 \\
(0.1 \%)\end{array}$ & $\begin{array}{c}5.688 \\
(-1.0 \%)\end{array}$ & $\begin{array}{c}5.710 \\
(-0.6 \%)\end{array}$ & $\begin{array}{c}8.979 \\
(4.9 \%)\end{array}$ & $\begin{array}{c}8.050 \\
(-5.9 \%)\end{array}$ & $\begin{array}{c}8.218 \\
(-4.0 \%)\end{array}$ & $\begin{array}{l}4.925 \\
(2.8 \%)\end{array}$ & $\begin{array}{c}4.715 \\
(-1.6 \%)\end{array}$ & $\begin{array}{c}4.711 \\
(-1.6 \%)\end{array}$ \\
\hline $\mathrm{MoO}_{3}[172]$ & $o P 16$ & $\begin{array}{c}\text { Pbnm } \\
\text { (62) }\end{array}$ & $\begin{array}{l}14.477 \\
(4.5 \%)\end{array}$ & $\begin{array}{l}13.380 \\
(-3.5 \%)\end{array}$ & $\begin{array}{l}13.515 \\
(-2.5 \%)\end{array}$ & $\begin{array}{l}3.695 \\
(0 \%)\end{array}$ & $\begin{array}{l}3.697 \\
(0 \%)\end{array}$ & $\begin{array}{c}3.692 \\
(-0.1 \%)\end{array}$ & $\begin{array}{c}3.972 \\
(0.2 \%)\end{array}$ & $\begin{array}{c}3.955 \\
(-0.2 \%)\end{array}$ & $\begin{array}{c}3.941 \\
(-0.5 \%)\end{array}$ \\
\hline $\mathrm{WO}_{3}[173]$ & $t P 8$ & $\begin{array}{l}P 4 / n m m \\
(129)\end{array}$ & $\begin{array}{l}5.314 \\
(0.2 \%)\end{array}$ & $\begin{array}{c}5.294 \\
(-0.2 \%)\end{array}$ & $\begin{array}{c}5.297 \\
(-0.1 \%)\end{array}$ & & & & & $\begin{array}{c}4.018 \\
(2.1 \%)\end{array}$ & $\begin{array}{c}4.014 \\
(2.0 \%)\end{array}$ \\
\hline $\mathrm{Mn}_{2} \mathrm{O}_{7}[174]$ & $m P 72$ & $\begin{array}{c}P 2_{1} / c \\
(14)\end{array}$ & $\begin{array}{l}6.986 \\
(2.8 \%)\end{array}$ & $\begin{array}{c}6.693 \\
(-1.5 \%)\end{array}$ & $\begin{array}{c}6.697 \\
(-1.4 \%)\end{array}$ & $\begin{array}{l}17.504 \\
(4.9 \%)\end{array}$ & $\begin{array}{l}16.494 \\
(-1.2 \%)\end{array}$ & $\begin{array}{l}16.493 \\
(-1.2 \%)\end{array}$ & $\begin{array}{c}9.598 \\
(1.5 \%)\end{array}$ & $\begin{array}{c}9.023 \\
(-4.6 \%)\end{array}$ & $\begin{array}{c}9.063 \\
(-4.1 \%)\end{array}$ \\
\hline $\mathrm{Tc}_{2} \mathrm{O}_{7}[175]$ & $o P 36$ & Pbca (61) & $\begin{array}{l}13.852 \\
(0.7 \%)\end{array}$ & $\begin{array}{l}13.543 \\
(-1.5 \%)\end{array}$ & $\begin{array}{l}13.535 \\
(-1.6 \%)\end{array}$ & $\begin{array}{c}7.600 \\
(2.2 \%)\end{array}$ & $\begin{array}{c}6.908 \\
(-7.1 \%)\end{array}$ & $\begin{array}{c}7.033 \\
(-5.5 \%)\end{array}$ & $\begin{array}{l}5.762 \\
(2.6 \%)\end{array}$ & $\begin{array}{c}5.337 \\
(-5.0 \%)\end{array}$ & $\begin{array}{c}5.353 \\
(-4.7 \%)\end{array}$ \\
\hline $\mathrm{RuO}_{4}[176]$ & $c P 40$ & $\begin{array}{c}P-43 n \\
(218)\end{array}$ & $\begin{array}{c}8.761 \\
(3.0 \%)\end{array}$ & $\begin{array}{c}8.254 \\
(-3.0 \%)\end{array}$ & $\begin{array}{c}8.359 \\
(-1.8 \%)\end{array}$ & & & & & & \\
\hline $\mathrm{RuO}_{4}[176]$ & $m S 20$ & $\begin{array}{l}C 2 / c \\
(15)\end{array}$ & $\begin{array}{c}9.562 \\
(2.8 \%)\end{array}$ & $\begin{array}{c}9.092 \\
(-2.3 \%)\end{array}$ & $\begin{array}{c}9.146 \\
(-1.7 \%)\end{array}$ & $\begin{array}{c}4.534 \\
(3.1 \%)\end{array}$ & $\begin{array}{c}4.231 \\
(-3.8 \%)\end{array}$ & $\begin{array}{c}4.318 \\
-1.8 \%)\end{array}$ & $\begin{array}{c}8.673 \\
(2.6 \%)\end{array}$ & $\begin{array}{c}8.177 \\
(-3.3 \%)\end{array}$ & $\begin{array}{c}8.285 \\
(-2.0 \%)\end{array}$ \\
\hline $\mathrm{OsO}_{4}$ [177] & $m S 20$ & $\begin{array}{l}C 2 / c \\
(15)\end{array}$ & $\begin{array}{c}9.514 \\
(1.4 \%)\end{array}$ & $\begin{array}{c}9.066 \\
(-3.3 \%)\end{array}$ & $\begin{array}{c}9.058 \\
(-3.4 \%)\end{array}$ & $\begin{array}{c}4.572 \\
(1.3 \%)\end{array}$ & $\begin{array}{c}4.321 \\
(-4.3 \%)\end{array}$ & $\begin{array}{c}4.327 \\
(-4.2 \%)\end{array}$ & $\begin{array}{l}8.632 \\
(0 \%)\end{array}$ & $\begin{array}{c}8.212 \\
(-4.8 \%)\end{array}$ & $\begin{array}{c}8.250 \\
(-4.4 \%)\end{array}$ \\
\hline
\end{tabular}

a DFT-D3 with zero-damping scheme [41]. ${ }^{\mathrm{b}}$ DFT-D3 with Becke-Johnson damping scheme [178].

While DFT-PBE0/TZVP without dispersion correction results in the overestimation of the lattice parameters, the D3 dispersion correction typically significantly underestimates the lattice parameters. For example, the error in lattice constant $b$ of $\mathrm{Tc}_{2} \mathrm{O}_{7}-7 \%$ for DFTD3(ZD), compared with $+2 \%$ without dispersion correction. Most of the studied molecular crystals show ionic bonding, which may be a challenging situation for the DFT-D3 scheme. We also tested the effects of the three-body dispersion term (ABC) on some molecular crystals but found only a negligible effect and no significant improvements.

\subsection{Mercury Oxides}

Finally, we discuss in more detail some mercury oxides which are rarely mentioned in the literature and have never been carefully studied: $\alpha-\mathrm{HgO}_{2}(m S 6)$ with space group $C 2 / m$ (no. 12) and $\beta-\mathrm{HgO}_{2}$ (oP12) with space group Pbca (no. 61) (Figure 11) [179-182]. The crystal structure of $\alpha-\mathrm{HgO}_{2}$ has been refined assuming a monoclinic symmetry, yielding a distorted CsCl-type structure. Originally, a rhombohedral unit cell with $\alpha$ close to $90^{\circ}$ was proposed [181]. $\beta-\mathrm{HgO}_{2}$ has been studied more extensively and adopts a distorted version of the cubic $\mathrm{MgO}_{2}$ structure of group 12 oxides $\mathrm{ZnO}_{2}$ and $\mathrm{CdO}_{2}$ [179-181]. 
(a)

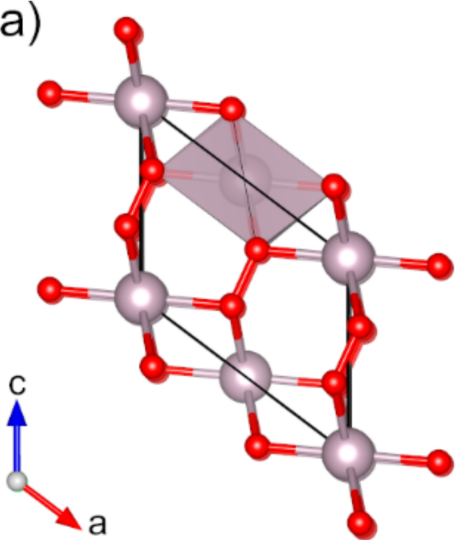

(b)

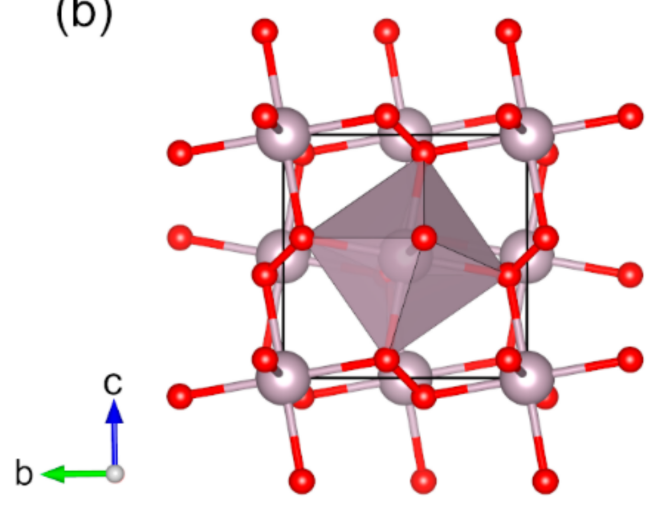

Figure 11. Optimized structures of (a) $\alpha-\mathrm{HgO}_{2}(m S 6)$ and (b) $\beta-\mathrm{HgO}_{2}(o P 12)$ (red: oxygen, almond: mercury). Coordination octahedra of $\mathrm{Hg}$ atoms are shown in almond color.

Based on our calculations, errors in the lattice parameters $a, b$, and $c$, compared with experimental data are $+35.9 \%,-25.5 \%$, and $30.5 \%$ for $\alpha-\mathrm{HgO}_{2}(m S 6)$ and $-10.0 \%,-8.9 \%$, and $+13.8 \%$ for $\beta-\mathrm{HgO}_{2}(o P 12)$. Such large errors were not observed for any other d-metal oxide included in the study. The errors are not expected to be due to the DFT-PBE0 method or the used basis set, because the other studied mercury oxides, $\mathrm{HgO}(o P 8)$ and $\mathrm{HgO}(h P 6)$, are described well by DFT-PBE0 (the errors in the lattice parameters are less than 1.3\%) (see Supplementary Materials). Our findings motivate further experimental studies on the crystal structures of these oxides. For $\beta-\mathrm{HgO}_{2}$, our final optimized geometry corresponds to the cubic $\mathrm{MgO}_{2}$ structure in space group $\mathrm{Pa}-3$ (no. 205). No imaginary vibrational frequencies were observed when a harmonic frequency calculation was carried out in this space group.

\section{Materials and Methods}

All quantum chemical calculations were carried out using the CRYSTAL14 and CRYSTAL17 program packages $[40,183]$. The structures were fully optimized within the applied space groups by using hybrid PBE0 density functional method (DFT-PBE0, 25\% exact exchange) $[184,185]$. All-electron, Gaussian-type triple- $\zeta$-valence + polarization (TZVP) basis sets based on Karlsruhe def2 basis sets were utilized [186]. Scalar relativistic effects were taken into account by means of relativistic effective core potentials for elements Y-Hg. The molecular basis sets were adapted for solid-state calculations, and all basis sets are given as Supplementary Materials. Furthermore, the results obtained with a smaller split-valence + polarization (SVP) basis set are reported in the Supplementary Materials. For some molecular and layered oxides, where weak intermolecular or interlayer interactions could play a role, Grimme's D3 dispersion correction scheme was tested both with zero-damping and Becke-Johnson damping $[41,178,187]$. List of the Monkhorst-Pack-type $k$-meshes used for sampling the reciprocal space is given in the Supplementary Materials. Spin-unrestricted formalism was used for all magnetic $d$-metal oxides. Tightened tolerance factors (TOLINTEG) of 8, 8, 8, 8, and 16 were used for the evaluation of the Coulomb and exchange integrals. Default geometry optimization criteria and DFT integration grids of CRYSTAL were used. Harmonic frequency calculations were carried out as implemented in the CRYSTAL software [188,189].

In general, calculations on magnetic oxides were carried out with the following strategy: if experimental data on the magnetic ground state of the crystal structure were available, the reported ground state was calculated. However, there are crystal structures which are only reported as paramagnetic at the room temperature, but the low-temperature magnetic ground state has not been reported. In such cases, we investigated their magnetic and diamagnetic ground states at $0 \mathrm{~K}$, testing various diamagnetic (DM), ferromagnetic (FM), ferrimagnetic (FiM), or antiferromagnetic (AFM) configurations to find the ener- 
getically favorable spin configuration (relative energies are given in the Supplementary Materials). We also checked different spin configurations for crystal structures where the magnetic ground state is not known from the experiment. Spin-orbit coupling was not taken into account in the calculations, as spin-orbit coupling is not yet available in the public version of the CRYSTAL code.

All experimental crystal structures were taken from Inorganic Crystal Structure Database (ICSD) [190] or from the Crystallography Open Database (COD) [191,192]. The structures optimized at the DFT-PBE0/TZVP level of theory, including spin configurations for magnetic structures, are available as Supplementary Materials. Structural figures were created using the VESTA software [193].

\section{Conclusions}

We have carried out a comprehensive and systematic computational study of 100 bulk binary $d$-metal oxides by hybrid DFT-PBE0 method. We reported detailed information on the crystal structures including space groups, spin configurations, band gaps, and atomic magnetic moments, which are consistent with the experimental data. For the first time, we found a few problematic cases such as $\alpha$ - and $\beta-\mathrm{HgO}_{2}$ where crystallographic data, considered to be correct for a long time, seem to be inaccurate. We identified the magnetic ground state of the crystal structures at $0 \mathrm{~K}$, which are known to be paramagnetic. Our study shows that hybrid DFT methods represent a reliable methodology for the description of such strongly correlated systems as $d$-metal oxides. The database facilitates future studies on the more complex properties of the binary $d$-metal oxides and provides a dataset for benchmarking new computational methods.

Supplementary Materials: The following supporting information can be downloaded online. Table S1: Summary of the studied binary d-metal oxides, Table S2: Lattice parameters of the studied binary d-metal oxides, and Table S3: Energy comparisons of different magnetic configurations for the paramagnetic binary d-metal oxides. All structural data in CIF format, GTO basis sets used in the calculations.

Author Contributions: Conceptualization, A.J.K.; methodology, M.S.K. and K.E.; investigation, M.S.K., K.E., J.L., A.R. and N.T.; data curation, K.E.; writing-original draft preparation, M.S.K.; writing-review and editing, K.E. and A.J.K.; visualization, M.S.K.; supervision, A.J.K.; funding acquisition, A.J.K. All authors have read and agreed to the published version of the manuscript.

Funding: This research was funded by the Academy of Finland, grant number 317273.

Institutional Review Board Statement: Not applicable.

Informed Consent Statement: Not applicable.

Data Availability Statement: An up-to-date Git repository of the studied $d$-metal oxides is available at https:/ / github.com/aalto-imm/d-oxides (accessed on 30 December 2021).

Acknowledgments: The computing resources from CSC, the Finnish IT Center for Science, are gratefully acknowledged.

Conflicts of Interest: The authors declare no conflict of interest.

\section{References}

1. Nilius, N. Properties of Oxide Thin Films and Their Adsorption Behavior Studied by Scanning Tunneling Microscopy and Conductance Spectroscopy. Surf. Sci. Rep. 2009, 64, 595-659. [CrossRef]

2. Giordano, L.; Pacchioni, G. Oxide Films at the Nanoscale: New Structures, New Functions, and New Materials. Acc. Chem. Res. 2011, 44, 1244-1252. [CrossRef]

3. Honkala, K. Tailoring Oxide Properties: An Impact on Adsorption Characteristics of Molecules and Metals. Surf. Sci. Rep. 2014, 69, 366-388. [CrossRef]

4. Tripathi, T.S.; Karppinen, M. Atomic Layer Deposition of P-Type Semiconducting Thin Films: A Review. Adv. Mater. Interfaces 2017, 4, 1-16. [CrossRef]

5. Walia, S.; Balendhran, S.; Nili, H.; Zhuiykov, S.; Rosengarten, G.; Wang, Q.H.; Bhaskaran, M.; Sriram, S.; Strano, M.S.; Kalantarzadeh, K. Transition Metal Oxides-Thermoelectric Properties. Prog. Mater. Sci. 2013, 58, 1443-1489. [CrossRef] 
6. Rao, C.N.R. Transition Metal Oxides. Annu. Rev. Phys. Chem. 1989, 40, 291-326. [CrossRef]

7. Dixon, S.C.; Scanlon, D.O.; Carmalt, C.J.; Parkin, I.P. N-Type Doped Transparent Conducting Binary Oxides: An Overview. J. Mater. Chem. C 2016, 4, 6946-6961. [CrossRef]

8. Wang, L.; Maxisch, T.; Ceder, G. Oxidation Energies of Transition Metal Oxides within the GGA+U Framework. Phys. Rev. B 2006, 73, 195107. [CrossRef]

9. Schrön, A.; Rödl, C.; Bechstedt, F. Crystalline and Magnetic Anisotropy of the 3d-Transition Metal Monoxides MnO, FeO, CoO, and NiO. Phys. Rev. B 2012, 86, 115134. [CrossRef]

10. Noh, J.; Osman, O.I.; Aziz, S.G.; Winget, P.; Brédas, J.L. A Density Functional Theory Investigation of the Electronic Structure and Spin Moments of Magnetite. Sci. Technol. Adv. Mater. 2014, 15, 044202. [CrossRef]

11. Lima, A.F. Density Functional Theory Study on the Magnetic Properties of $\mathrm{Co}_{3} \mathrm{O}_{4}$ with Normal Spinel Structure. J. Phys. Chem. Solids 2016, 91, 86-89. [CrossRef]

12. Singh, V.; Kosa, M.; Majhi, K.; Major, D.T. Putting DFT to the Test: A First-Principles Study of Electronic, Magnetic, and Optical Properties of $\mathrm{Co}_{3} \mathrm{O}_{4}$. J. Chem. Theory Comput. 2015, 11, 64-72. [CrossRef] [PubMed]

13. Deng, H.X.; Li, J.; Li, S.S.; Xia, J.B.; Walsh, A.; Wei, S.H. Origin of Antiferromagnetism in CoO: A Density Functional Theory Study. Appl. Phys. Lett. 2010, 96, 162508. [CrossRef]

14. Bredow, T.; Gerson, A.R. Effect of Exchange and Correlation on Bulk Properties of MgO, NiO, and CoO. Phys. Rev. B 2000, 61, 5194-5201. [CrossRef]

15. Rollmann, G.; Rohrbach, A.; Entel, P.; Hafner, J. First-Principles Calculation of the Structure and Magnetic Phases of Hematite. Phys. Rev. B 2004, 69, 165107. [CrossRef]

16. Linnera, J.; Karttunen, A.J. Ab Initio Study of the Lattice Thermal Conductivity of $\mathrm{Cu}_{2} \mathrm{O}$ Using the Generalized Gradient Approximation and Hybrid Density Functional Methods. Phys. Rev. B 2017, 96, 014304. [CrossRef]

17. Rödl, C.; Fuchs, F.; Furthmüller, J.; Bechstedt, F. Quasiparticle Band Structures of the Antiferromagnetic Transition-Metal Oxides $\mathrm{MnO}, \mathrm{FeO}, \mathrm{CoO}$, and NiO. Phys. Rev. B 2009, 79, 235114. [CrossRef]

18. Kulik, H.J.; Marzari, N. Transition-Metal Dioxides: A Case for the Intersite Term in Hubbard-Model Functionals. J. Chem. Phys. 2011, 134, 094103. [CrossRef]

19. Chen, X.; Parker, D.; Du, M.H.; Singh, D.J. Potential Thermoelectric Performance of Hole-Doped Cu 2 O. New J. Phys. 2013, 15, 043029. [CrossRef]

20. Seo, D.H.; Urban, A.; Ceder, G. Calibrating Transition-Metal Energy Levels and Oxygen Bands in First-Principles Calculations: Accurate Prediction of Redox Potentials and Charge Transfer in Lithium Transition-Metal Oxides. Phys. Rev. B 2015, 92 , 115118. [CrossRef]

21. Kirchner-Hall, N.E.; Zhao, W.; Xiong, Y.; Timrov, I.; Dabo, I. Extensive Benchmarking of DFT+U Calculations for Predicting Band Gaps. Appl. Sci. 2021, 11, 2395. [CrossRef]

22. Gillen, R.; Robertson, J. Accurate Screened Exchange Band Structures for the Transition Metal Monoxides MnO, FeO, CoO and NiO. J. Phys. Condens. Matter 2013, 25, 165502. [CrossRef] [PubMed]

23. Zhao, Q.; Kulik, H.J. Where Does the Density Localize in the Solid State? Divergent Behavior for Hybrids and DFT+U. J. Chem. Theory Comput. 2018, 14, 670-683. [CrossRef] [PubMed]

24. Sun, J.; Ruzsinszky, A.; Perdew, J. Strongly Constrained and Appropriately Normed Semilocal Density Functional. Phys. Rev. Lett. 2015, 115, 1-6. [CrossRef] [PubMed]

25. Lane, C.; Furness, J.W.; Buda, I.G.; Zhang, Y.; Markiewicz, R.S.; Barbiellini, B.; Sun, J.; Bansil, A. Antiferromagnetic Ground State of La2CuO4: A Parameter-Free Ab Initio Description. Phys. Rev. B 2018, 98, 125140. [CrossRef]

26. Kylänpää, I.; Balachandran, J.; Ganesh, P.; Heinonen, O.; Kent, P.R.C.; Krogel, J.T. Accuracy of Ab Initio Electron Correlation and Electron Densities in Vanadium Dioxide. Phys. Rev. Mater. 2017, 1, 065408. [CrossRef]

27. Tran, F.; Stelzl, J.; Blaha, P. Rungs 1 to 4 of DFT Jacob's Ladder: Extensive Test on the Lattice Constant, Bulk Modulus, and Cohesive Energy of Solids. J. Chem. Phys. 2016, 144. [CrossRef]

28. Isaacs, E.B.; Wolverton, C. Performance of the Strongly Constrained and Appropriately Normed Density Functional for Solid-State Materials. Phys. Rev. Mater. 2018, 2, 063801. [CrossRef]

29. Charles, N.; Rondinelli, J.M. Assessing Exchange-Correlation Functional Performance for Structure and Property Predictions of Oxyfluoride Compounds from First Principles. Phys. Rev. B 2016, 94. [CrossRef]

30. Kuklin, M.S.; Karttunen, A.J. Crystal Structure Prediction of Magnetic Transition Metal Oxides by Using Evolutionary Algorithm and Hybrid DFT Methods. J. Phys. Chem. C 2018, 122, 24949-24957. [CrossRef]

31. Brugnoli, L.; Ferrari, A.M.; Civalleri, B.; Pedone, A.; Menziani, M.C. Assessment of Density Functional Approximations for Highly Correlated Oxides: The Case of $\mathrm{CeO}_{2}$ and $\mathrm{Ce}_{2} \mathrm{O}_{3}$. J. Chem. Theory Comput. 2018, 14, 4914-4927. [CrossRef] [PubMed]

32. Civalleri, B.; Presti, D.; Dovesi, R.; Savin, A. On Choosing the Best Density Functional Approximation. In Chemical Modelling; Springborg, M., Ed.; Royal Society of Chemistry: Cambridge, UK, 2012; Volume 9, pp. 168-185. ISBN 978-1-84973-412-7.

33. Moreira, I.d.P.R.; Illas, F.; Martin, R.L. Effect of Fock Exchange on the Electronic Structure and Magnetic Coupling in NiO. Phys. Rev. B Condens. Matter Mater. Phys. 2002, 65, 1551021. [CrossRef]

34. Linnera, J.; Sansone, G.; Maschio, L.; Karttunen, A.J. Thermoelectric Properties of P-Type $\mathrm{Cu}_{2} \mathrm{O}, \mathrm{CuO}$, and NiO from $\mathrm{Hybrid}$ Density Functional Theory. J. Phys. Chem. C 2018, 122, 15180-18189. [CrossRef] [PubMed] 
35. Das, T.; Liberto, D.G.; Tosoni, S.; Pacchioni, G. Band Gap of 3d Metal Oxides and Quasi-2D Materials from Hybrid Density Functional Theory: Are Dielectric-Dependent Functionals Superior? J. Chem. Theory Comput. 2019, 16, 3786-3798. [CrossRef] [PubMed]

36. Cipriano, L.A.; Liberto, D.G.; Tosoni, S.; Pacchioni, G. Band Gap in Magnetic Insulators from a Charge Transition Level Approach. J. Chem. Theory Comput. 2019, 15, 6294-6312. [CrossRef] [PubMed]

37. Li, W.; Walther, C.F.J.; Kuc, A.; Heine, T. Density Functional Theory and Beyond for Band-Gap Screening: Performance for Transition-Metal Oxides and Dichalcogenides. J. Chem. Theory Comput. 2013, 9, 2950-2958. [CrossRef] [PubMed]

38. Posysaev, S.; Miroshnichenko, O.; Alatalo, M.; Le, D.; Rahman, T.S. Oxidation States of Binary Oxides from Data Analytics of the Electronic Structure. Comput. Mater. Sci. 2019, 161, 403-414. [CrossRef]

39. Dovesi, R.; Erba, A.; Orlando, R.; Zicovich-Wilson, C.M.; Civalleri, B.; Maschio, L.; Rérat, M.; Casassa, S.; Baima, J.; Salustro, S.; et al. Quantum-Mechanical Condensed Matter Simulations with CRYSTAL. Wiley Interdiscip. Rev. Comput. Mol. Sci. 2018, 8, 1-36. [CrossRef]

40. Grimme, S.; Antony, J.; Ehrlich, S.; Krieg, H. A Consistent and Accurate Ab Initio Parametrization of Density Functional Dispersion Correction (DFT-D) for the 94 Elements H-Pu. J. Chem. Phys. 2010, 132, 154104. [CrossRef]

41. Honig, J.M.; Reed, T.B. Electrical Properties of $\mathrm{Ti}_{2} \mathrm{O}_{3}$ Single Crystals. Phys. Rev. 1968, 174, 1020-1026. [CrossRef]

42. Ohkoshi, S.; Tsunobuchi, Y.; Matsuda, T.; Hashimoto, K.; Namai, A.; Hakoe, F.; Tokoro, H. Synthesis of a Metal Oxide with a Room-Temperature Photoreversible Phase Transition. Nat. Chem. 2010, 2, 539-545. [CrossRef] [PubMed]

43. Tanaka, K.; Nasu, T.; Miyamoto, Y.; Ozaki, N.; Tanaka, S.; Nagata, T.; Hakoe, F.; Yoshikiyo, M.; Nakagawa, K.; Umeta, Y.; et al. Structural Phase Transition between Lambda- $\mathrm{Ti}_{3} \mathrm{O}_{5}$ and Delta- $\mathrm{Ti}_{3} \mathrm{O}_{5}$ by Breaking of a One-Dimensionally Conducting Pathway Cryst. Growth Des. 2015, 15, 653-657. [CrossRef]

44. Moon, R.M. Antiferromagnetism in $\mathrm{V}_{2} \mathrm{O}_{3}$. Phys. Rev. Lett. 1970, 25, 527-529. [CrossRef]

45. Thomas, G.A.; Rapkine, D.H.; Carter, S.A.; Millis, A.J. Observation of the Gap and Kinetic Energy in a Correlated Insulator. Phys. Rev. Lett. 1994, 73, 1529-1532. [CrossRef]

46. Berglund, C.N.; Guggenheim, H.J. Electronic Properties of $\mathrm{VO}_{2}$ near the Semiconductor-Metal Transition. Phys. Rev. 1969, 185, 1022-1033. [CrossRef]

47. Hill, A.H.; Harrison, A.; Dickinson, C.; Zhou, W.; Kockelmann, W. Crystallographic and Magnetic Studies of Mesoporous Eskolaite, $\mathrm{Cr}_{2} \mathrm{O}_{3}$. Microporous Mesoporous Mater. 2010, 130, 280-286. [CrossRef]

48. Crawford, J.A.; Vest, R.W. Electrical Conductivity of Single-Crystal $\mathrm{Cr}_{2} \mathrm{O}_{3}$. J. Appl. Phys. 1964, 35, 2413-2418. [CrossRef]

49. Cheng, C.-S.; Gomi, H.; Sakata, H. Electrical and Optical Properties of Cr2O3 Films Prepared by Chemical Vapour Deposition. Phys. Stat. Sol. 1996, 155, 417-425. [CrossRef]

50. Kubota, B. Preparation of Ferromagnetic Chromium Dioxide. J. Phys. Soc. Jpn. 1960, 15, 1706. [CrossRef]

51. Cheetham, A.K.; Hope, D.A.O. Magnetic Ordering and Exchange Effects in the Antiferromagnetic Solid Solutions MnxNi1-XO. Phys. Rev. B 1983, 27, 6964-6967. [CrossRef]

52. Drabkin, I.A.; Emel'yanova, L.T.; Iskenderov, R.N.; Ksendzov, Y.M. Photoconductivity of Single Crystals of MnO. Sov. Phys. Solid State 1969, 10, 2428

53. Iskenderov, R.N.; Drabkin, I.A.; Evel'yanova, L.T.; Ksendzov, Y.M. Absorption Spectrum of MnO Single Crystals. Sov. Phys. Solid State 1969, 10, 2031

54. Cockayne, E.; Levin, I.; Wu, H.; Llobet, A. The Magnetic Structure of Bixbyite $\alpha-\mathrm{Mn}_{2} \mathrm{O}_{3}$ : A Combined Density Functional Theory DFT $+U$ and Neutron Diffraction Study. Phys. Rev. B 2012, 87, 184413. [CrossRef]

55. Regulski, M.; Przeniosło, R.; Sosnowska, I.; Hohlwein, D.; Schneider, R. Neutron Diffraction Study of the Magnetic Structure of $\alpha-\mathrm{Mn}_{2} \mathrm{O}_{3}$. J. Alloys Compd. 2004, 362, 236-240. [CrossRef]

56. Sharma, S.; Chauhan, P.; Husain, S. Structural and Optical Properties of $\mathrm{Mn}_{2} \mathrm{O}_{3}$ Nanoparticles \& Its Gas Sensing Applications. Adv. Mater. Proc. 2016, 2, 220-225. [CrossRef]

57. Awad, H.D.; Elttayef, A.K.; Ressen, A.L.; Ali, K.A. The Effect of Annealing on the Structural and Optical Properties of $\mathrm{Mn}_{2} \mathrm{O}_{3}$ Thin Film Prepared by Chemical Spray Pyrolysis. Int. J. Sci. Res. 2017, 6, 291-294. [CrossRef]

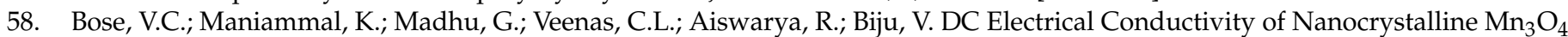
Synthesized through a Novel Sol-Gel Route. Int. Conf. Mater. Sci. Technol. 2015, 73, 012084. [CrossRef]

59. Gao, T.; Glerup, M.; Krumeich, F.; Nesper, R.; Fjellvåg, H.; Norby, P. Microstructures and Spectroscopic Properties of CryptomelaneType Manganese Dioxide Nanofibers. J. Phys. Chem. C 2008, 112, 13134-13140. [CrossRef]

60. Li, T.; Wu, J.; Xiao, X.; Zhang, B.; Hu, Z.; Zhou, J. Band Gap Engineering of $\mathrm{MnO}_{2}$ through in Situ Al-Doping for Applicable Pseudocapacitors. RCS Adv. 2016, 6, 13914-13919. [CrossRef]

61. Druilhe, R.; Suchet, J.P. Electron Transport in $\mathrm{CrO}_{2}$ and $\mathrm{Mn}_{\mathrm{x}} \mathrm{Cr}_{1-\mathrm{X}} \mathrm{O}_{2}$. Czech. J. Phys. B 1967, 17, 337-346. [CrossRef]

62. Greedan, J.E.; Raju, N.P.; Wills, A.S.; Morin, C.; Shaw, S.M.; Reimers, J.N. Structure and Magnetism in $\lambda-\mathrm{MnO}_{2}$. Geometric Frustration in a Defect Spinel. Chem. Mater. 1998, 10, 3058-3067. [CrossRef]

63. Bhargande, S.K.; Patil, P.S. Structural, Optical Investigation of Manganese Oxide Thin Films by Spray Pyrolysis Technique. Res. Rev. J. Pure Appl. Phys. Struct 2013, 1, 19-23.

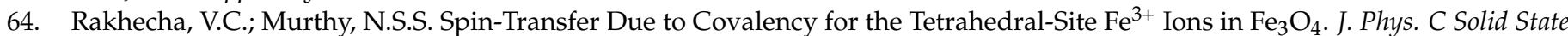
Phys. 1978, 11, 4389-4404. [CrossRef] 
65. Wright, J.P.; Attfield, J.P.; Radaelli, P.G. Charge Ordered Structure of Magnetite $\mathrm{Fe}_{3} \mathrm{O}_{4}$ below the Verwey Transition. Phys. Rev. B 2002, 66, 214422. [CrossRef]

66. Krén, E.; Szabó, P.; Konczos, G. Neutron Diffraction Studies on the (1-x) $\mathrm{Fe}_{2} \mathrm{O}_{3}-\mathrm{xRh}_{2} \mathrm{O}_{3}$ System. Phys. Lett. 1965, 19, 103-104 [CrossRef]

67. Maslen, E.N.; Streltsov, V.A.; Streltsova, N.R.; Ishizawa, N. Synchrotron X-Ray Study of the Electron Density in $\alpha$-Fe $\mathrm{O}_{3}$. Acta Crystallogr. Sect. B Struct. Sci. 1994, 50, 435-441. [CrossRef]

68. Finger, L.W.; Hazen, R.M. Crystal Structure and Isothermal Compression of $\mathrm{Fe}_{2} \mathrm{O}_{3}, \mathrm{Cr}_{2} \mathrm{O}_{3}$, and $\mathrm{V}_{2} \mathrm{O}_{3}$ to 50 kbars. J. Appl. Phys. 1980, 51, 5362-5367. [CrossRef]

69. Malina, O.; Tuček, J.; Jakubec, P.; Kašlík, J.; Medřík, I.; Tokoro, H.; Yoshikiyo, M.; Namai, A.; Ohkoshi, S.; Zbořil, R. Magnetic Ground State of Nanosized $\beta-\mathrm{Fe} 2 \mathrm{O} 3$ and Its Remarkable Electronic Features. RSC Adv. 2015, 5, 49719-49727. [CrossRef]

70. Yoshikiyo, M.; Yamada, K.; Namai, A.; Ohkoshi, S.-I. Study of the Electronic Structure and Magnetic Properties of $\varepsilon$-Fe ${ }_{2} \mathrm{O}_{3}$ by First-Principles Calculation and Molecular Orbital Calculations. J. Phys. Chem. C 2012, 116, 8688-8691. [CrossRef]

71. Khan, D.C.; Erickson, R.A. Magnetic Form Factor of Co++ Ion in Cobaltous Oxide. Phys. Rev. B 1970, 1, 2243-2249. [CrossRef]

72. Herrmann-Ronzaud, D.; Burlet, P.; Rossat-Mignod, J. Equivalent Type-II Magnetic Structures: CoO, a Collinear Antiferromagnet. J. Phys. C Solid State Phys. 1978, 11, 2123-2137. [CrossRef]

73. Sasaki, S.; Fujino, K.; Takéuchi, Y. X-Ray Determination of Electron-Density Distributions in Oxides, MgO, MnO, CoO, and NiO, and Atomic Scattering Factors of Their Constituent Atoms. Proc. Jpn. Acad. Ser. B Phys. Biol. Sci. 1979, 55, 43-48. [CrossRef]

74. Ikedo, Y.; Sugiyama, J.; Nozaki, H.; Itahara, H.; Brewer, J.H.; Ansaldo, E.J.; Morris, G.D.; Andreica, D.; Amato, A. Spatial Inhomogeneity of Magnetic Moments in the Cobalt Oxide Spinel $\mathrm{Co}_{3} \mathrm{O}_{4}$. Phys. Rev. B Condens. Matter Mater. Phys. 2007, 75, 1-8. [CrossRef]

75. Roth, W.L. The Magnetic Structure of $\mathrm{Co}_{3} \mathrm{O}_{4}$. J. Phys. Chem. Solids 1964, 25, 1-10. [CrossRef]

76. Qiao, L.; Xiao, H.Y.; Meyer, H.M.; Sun, J.N.; Rouleau, C.M.; Puretzky, A.A.; Geohegan, D.B.; Ivanov, I.N.; Yoon, M.; Weber, W.J.; et al. Nature of the Band Gap and Origin of the Electro-/Photo-Activity of $\mathrm{Co}_{3} \mathrm{O}_{4}$. J. Mater. Chem. C 2013, 1, 4628-4633. [CrossRef]

77. Alperin, H.A. The Magnetic Form Factor of Nickel Oxide. J. Phys. Soc. Jpn. Suppl. B. 1962, 17, 12-15.

78. Fender, B.E.F.; Jacobson, A.J.; Wedgwood, F.A. Covalency Parameters in MnO, $\alpha-M n S$, and NiO. J. Chem. Phys. 1968, 48, 990-994. [CrossRef]

79. Hüfner, S.; Osterwalder, J.; Riesterer, T.; Hulliger, F. Photoemission and Inverse Photoemission Spectroscopy of NiO. Solid State Commun. 1984, 52, 793-796. [CrossRef]

80. Sawatzky, G.A.; Allen, J.W. Magnitude and Origin of the Band Gap in NiO. Phys. Rev. Lett. 1984, 53, 2339-2342. [CrossRef]

81. Forsyth, J.B.; Brown, P.J.; Wanklyn, B.M. Magnetism in Cupric Oxide. J. Phys. C Solid State Phys. 1988, 21, 2917-2929. [CrossRef]

82. Yang, B.X.; Thurston, T.R.; Tranquada, J.M.; Shirane, G. Magnetic Neutron Scattering Study of Single-Crystal Cupric Oxide. Phys. Rev. B 1989, 39, 4343-4349. [CrossRef] [PubMed]

83. Yang, B.; Tranquada, J.; Shirane, G. Neutron Scattering Studies of the Magnetic Structure of Cupric Oxide. Phys. Rev. B Condens. Matter Mater. Phys. 1988, 38, 174-178. [CrossRef] [PubMed]

84. Marabelli, F.; Parravicini, G.B.; Salghetti-Drioli, F. Optical Gap of CuO. Phys. Rev. B 1995, 52, 1433-1436. [CrossRef] [PubMed]

85. Pinsard-Gaudart, L.; Rodriguez-Carvajal, J.; Gukasov, A.; Monod, P. Magnetic Properties of Paramelaconite $\left(\mathrm{Cu}_{4} \mathrm{O}_{3}\right)$ : A Pyrochlore Lattice with $\mathrm{S}=1 / 2$. Phys. Rev. B 2004, 69, 104408. [CrossRef]

86. Meyer, B.K.; Polity, A.; Reppin, D.; Becker, M.; Hering, P.; Klar, P.J.; Sander, T.; Reindl, C.; Benz, J.; Eickhoff, M.; et al. Binary Copper Oxide Semiconductors: From Materials towards Devices. Phys. Status Solidi B 2012, 249, 1487-1509. [CrossRef]

87. Berlijn, T.; Snijders, P.C.; Delaire, O.; Zhou, H.; Maier, T.A.; Cao, H.; Chi, S.; Matsuda, M.; Wang, Y.; Koehler, M.R.; et al. Itinerant Antiferromagnetism in $\mathrm{RuO}_{2}$. Phys. Rev. Lett. 2017, 118, 077201. [CrossRef]

88. Rice, C.E.; Robinson, W.R. Structural Changes Associated with the Semiconductor-to-Metal Transition in Ti ${ }_{2} \mathrm{O}_{3}$. Mater. Res. Bull. 1976, 11, 1355-1359. [CrossRef]

89. Guo, Y.; Clark, S.J.; Robertson, J. Electronic and Magnetic Properties of $\mathrm{Ti}_{2} \mathrm{O}_{3}, \mathrm{Cr}_{2} \mathrm{O}_{3}$, and $\mathrm{Fe}_{2} \mathrm{O}_{3}$ Calculated by the Screened Exchange Hybrid Density Functional. J. Phys. Condens. Matter 2012, 24, 325504. [CrossRef]

90. Onoda, M. Phase Transitions of $\mathrm{Ti}_{3} \mathrm{O}_{5}$. J. Solid State Chem. 1998, 136, 67-73. [CrossRef]

91. Steiner, H.; Turrillasb, X.; Steele, B.C.H. Phase Relationships and Electrical Properties of $\mathrm{Ti}_{3} \mathrm{O}_{5}, \mathrm{CrTi}_{2} \mathrm{O}_{5}$ and the PseudobrookiteType Systems $\mathrm{Mg}_{\mathrm{x}} \mathrm{Ti}_{3-\mathrm{X}} \mathrm{O}_{5}$ and $\mathrm{Li}_{\mathrm{x}} \mathrm{Ti}_{3-\mathrm{X}} \mathrm{O}_{5}$. J. Mater. Chem. 1992, 2, 1249-1256. [CrossRef]

92. Åsbrink, S.; Magnéli, A. Crystal Structure Studies on Trititanium Pentoxide, $\mathrm{Ti}_{3} \mathrm{O}_{5}$. Acta Crystallogr. 1959, 12, 575-581. [CrossRef]

93. Hong, B.Y.S.; Sbrink, S. The Structure of Gamma-Ti ${ }_{3} \mathrm{O}_{5}$ at 297 K. Acta Cryst. 1982, 2570-2576. [CrossRef]

94. Dernier, P.D.; Marezio, M. Crystal Structure of the Low-Temperature Antiferromagnetic Phase of $\mathrm{V}_{2} \mathrm{O}_{3}$. Phys. Rev. B 1970, 2 , 3771-3776. [CrossRef]

95. Dernier, P.D. The Crystal Structure of $\mathrm{V}_{2} \mathrm{O}_{3}$ and $\left(\mathrm{V}_{0.962} \mathrm{Cr}_{0.0382}\right)_{2} \mathrm{O}_{3}$ near the Metal-Insulator Transition. J. Phys. Chem. Solids 1970, 31, 2569-2575. [CrossRef]

96. Catti, M.; Sandrone, G.; Dovesi, R. Periodic Unrestricted Hartree-Fock Study of Corundum like $\mathrm{Ti}_{2} \mathrm{O}_{3}$ and $\mathrm{V}_{2} \mathrm{O}_{3}$. Phys. Rev. B Condens. Matter Mater. Phys. 1997, 55, 16122-16131. [CrossRef]

97. Qazilbash, M.M.; Schafgans, A.A.; Burch, K.S.; Yun, S.J.; Chae, B.G.; Kim, B.J.; Kim, H.T.; Basov, D.N. Electrodynamics of the Vanadium Oxides $\mathrm{VO}_{2}$ and $\mathrm{V}_{2} \mathrm{O}_{3}$. Phys. Rev. B Condens. Matter Mater. Phys. 2008, 77, 1-10. [CrossRef] 
98. Rogers, K.D. An X-ray Diffraction Study of Semiconductor and Metallic Vanadium Dioxide. Poweder Diffr. 1993, 8, $240-244$. [CrossRef]

99. Théobald, F.; Cabala, R.; Bernard, J. Essai Sur La Structure de $\mathrm{VO}_{2}$ (B). J. Solid State Chem. 1976, 17, 431-438. [CrossRef]

100. Kung, H.H. Transition Metal Oxides: Surface Chemistry and Catalysis; Elsevier: Amsterdam, The Netherlands, 1989.

101. Pintchovski, F.; Glaunsinger, W.S.; Navrotsky, A. Experimental Study of the Electronic and Lattice Contributions to the VO 2 Transition. J. Phys. Chem. Solids 1978, 39, 941-949. [CrossRef]

102. Park, J.H.; Coy, J.M.; Serkan Kasirga, T.; Huang, C.; Fei, Z.; Hunter, S.; Cobden, D.H. Measurement of a Solid-State Triple Point at the Metal-Insulator Transition in $\mathrm{VO}_{2}$. Nature 2013, 500, 431-434. [CrossRef]

103. Grau-Crespo, R.; Wang, H.; Schwingenschlögl, U. Why the Heyd-Scuseria-Ernzerhof Hybrid Functional Description of VO 2 Phases Is Not Correct. Phys. Rev. B Condens. Matter Mater. Phys. 2012, 86, 2-5. [CrossRef]

104. Burdett, J.K.; Miller, G.J.; Richardson, J.W.; Smith, V.J. Low-Temperature Neutron Powder Diffraction Study of Chromium Dioxide and the Validity of the Jahn-Teller Viewpoint. J. Am. Chem. Soc. 1988, 110, 8064-8071. [CrossRef]

105. Tan, M.; Tao, X. Ab Initio Electronic Structure of $\mathrm{CrO}_{2}$. Chin. Phys. Lett. 1999, 16, 199-201. [CrossRef]

106. Li, X.W.; Gupta, A.; Xiao, G. Influence of Strain on the Magnetic Properties of Epitaxial (100) Chromium Dioxide $\left(\mathrm{CrO}_{2}\right)$ Films. Appl. Phys. Lett. 1999, 75, 713-715. [CrossRef]

107. Yang, F.Y.; Chien, C.L.; Li, X.W.; Xiao, G.; Gupta, A. Critical Behavior of Epitaxial Half-Metallic Ferromagnetic $\mathrm{CrO}_{2}$ films. Phys. Rev. B Condens. Matter Mater. Phys. 2001, 63, 2-5. [CrossRef]

108. Blech, I.A.; Averbach, B.L. Spin Correlations in MnO. Physics 1964, 1, 31-44. [CrossRef]

109. Nam, K.M.; Kim, I.Y.; Jo, Y.; Lee, S.M.; Kim, B.G.; Choi, R.; Choi, I.S.; Song, H.; Park, J.T. New Crystal Structure: Synthesis and Characterization of Hexagonal Wurtzite MnO. J. Am. Chem. Soc. 2012, 134, 8392-8395. [CrossRef]

110. Schrön, A.; Rödl, C.; Bechstedt, F. Energetic Stability and Magnetic Properties of MnO in the Rocksalt, Wurtzite, and Zinc-Blende Structures: Influence of Exchange and Correlation. Phys. Rev. B Condens. Matter Mater. Phys. 2010, 82, 165109. [CrossRef]

111. Geller, S. Structure of Alpha- $\mathrm{Mn}_{2} \mathrm{O}_{3}$, $\left(\mathrm{Mn}_{0.983} \mathrm{Fe}_{0.017}\right)_{2} \mathrm{O}_{3}$ and $\left(\mathrm{Mn}_{0.37} \mathrm{Fe}_{0.63}\right)_{2} \mathrm{O}_{3}$ and Relation to Magnetic Ordering. Acta Crystallogr. Sect. B Struct. Crystallogr. Cryst. Chem. 1971, 27, 821-828. [CrossRef]

112. Norrestam, R. Alpha-Manganese (III) Oxide-a C-Type Sesquioxide of Orthorhombic Symmetry. Acta Chem. Scand. 1967, 21, 2871-2884. [CrossRef]

113. Chevalier, R.R.; Roult, G.; Bertaut, E.F. Etude Par Effet Mossbauer Du Systeme $\mathrm{Mn}_{2-\mathrm{X}} \mathrm{Fe}_{\mathrm{x}} \mathrm{O}_{3}$-et Transitions Magnetiques Dans $\mathrm{Mn}_{2} \mathrm{O}_{3}$ Par Diffraction Neutronique. Solid State Commun. 1967, 5, 7-11. [CrossRef]

114. Sharrouf, M.; Awad, R.; Roumié, M.; Marhaba, S. Structural, Optical and Room Temperature Magnetic Study of $\mathrm{Mn}_{2} \mathrm{O}_{3}$ Nanoparticles. Mater. Sci. Appl. 2015, 850-859. [CrossRef]

115. Satomi, K. Oxygen Positional Parameters of Tetragonal $\mathrm{Mn}_{3} \mathrm{O}_{4}$. J. Phys. Soc. Jpn. 1961, 16, 258-266. [CrossRef]

116. Paris, E.; Ross, I.; Charles, R.; Olijnyk, H. $\mathrm{Mn}_{3} \mathrm{O}_{4}$ at High Pressure: A Diamond-Anvil Cell Study and a Structural Modelling. Eur. J. Mineral. 1992, 4, 87-94. [CrossRef]

117. Franchini, C.; Podloucky, R.; Paier, J.; Marsman, M.; Kresse, G. Ground-State Properties of Multivalent Manganese Oxides: Density Functional and Hybrid Density Functional Calculations. Phys. Rev. B Condens. Matter Mater. Phys. 2007, 75, 195128. [CrossRef]

118. Chartier, A.; Arco, P.D.; Dovesi, R.; Giuria, P.; Torino, I.-; Saunders, V.R. Ab Initio Hartree-Fock Investigation of the Structural, Electronic, and Magnetic Properties of $\mathrm{Mn}_{3} \mathrm{O}_{4}$. Phys. Rev. B 1999, 60, 42-48. [CrossRef]

119. Rossouw, M.H.; Liles, D.C.; Thackeray, M.M. Alpha Manganese Dioxide for Lithium Batteries: A Structural and Electrochemical Study. Mat. Res. Bull. 1992, 27, 221-230. [CrossRef]

120. Fong, C.; Kennedy, B.J.; Elcombe, M.M. A Powder Neutron Diffraction Study of Lambda and Gamma Manganese Dioxide and of LiMn2O4. Z. Krist. 1994, 209, 941-945. [CrossRef]

121. Bolzan, A.A.; Fong, C.; Kennedy, B.J.; Howard, C.J. Powder Neutron Diffraction Study of Pyrolusite, Beta-MnO2. Aust. J. Chem. 1993, 46, 939-944. [CrossRef]

122. Vadlamani, B.; An, K.; Jagannathan, M.; Chandran, K.S.R. An In-Situ Electrochemical Cell for Neutron Diffraction Studies of Phase Transitions in Small Volume Electrodes of Li-Ion Batteries. J. Electrochem. Soc. 2014, 161, A1731-A1741. [CrossRef]

123. Yoshimori, A. A New Type of Antiferromagnetic Structure in the Rutile Type Crystal. J. Phys. Soc. Jpn. 1959, 14, 807-821. [CrossRef]

124. Sato, H.; Wakiya, K.; Enoki, T.; Kiyama, T.; Wakabayashi, Y.; Nakao, H.; Murakami, Y. Magnetic Structure of $\beta-\mathrm{MnO}_{2}:$ X-Ray Magnetic Scattering Study. J. Phys. Soc. Jpn. 2001, 70, 37-40. [CrossRef]

125. Yamamoto, N.; Endo, T.; Shimada, M.; Takada, T. Single Crystal Growth of Alpha-MnO2. Jpn. J. Appl. Phys. 1974, 13, 723-724. [CrossRef]

126. Guo, L.W.; Peng, D.L.; Makino, H.; Hanada, T.; Hong, S.K.; Sumiyama, K.; Yao, T.; Inaba, K. Structural Characteristics and Magnetic Properties of $\lambda-\mathrm{MnO}_{2}$ Films Grown by Plasma-Assisted Molecular Beam Epitaxy. J. Appl. Phys. 2001, 90, 351-354. [CrossRef]

127. Mazzocchi, V.L.; Parente, C.B.R. Refinement of the Ferri- and Paramagnetic Phases of Magnetite from Neutron Multiple Diffraction Data. J. Appl. Crystallogr. 1998, 31, 718-725. [CrossRef]

128. Cornell, R.M.; Schwertmann, U. The Iron Oxides: Structure, Properties, Reactions, Occurences, and Uses; Wiley: Weinheim, Germany, 2003; ISBN 978-3-527-60644-3. 
129. Masrour, R.; Hlil, E.K.; Hamedoun, M.; Benyoussef, A.; Mounkachi, O.; El Moussaoui, H. Electronic and Magnetic Structures of Fe3O4ferrimagnetic Investigated by First Principle, Mean Field and Series Expansions Calculations. J. Magn. Magn. Mater. 2015, 378, 37-40. [CrossRef]

130. Danno, T.; Nakatsuka, D.; Kusano, Y.; Asaoka, H.; Nakanishi, M.; Fujii, T.; Ikeda, Y.; Takada, J. Crystal Structure of $\beta$-Fe $2 \mathrm{O}_{3}$ and Topotactic Phase Transformation to $\alpha-\mathrm{Fe}_{2} \mathrm{O}_{3}$. Cryst. Growth Des. 2013, 13, 770-774. [CrossRef]

131. Kelm, K.; Mader, W. Synthesis and Structural Analysis of $\varepsilon-\mathrm{Fe}_{2} \mathrm{O}_{3}$. Z. Anorg. Allg. Chem. 2005, 631, 2383-2389. [CrossRef]

132. Svendsen, M.B. Beta-Fe2O3-Eine Neue Eisen(III)Oxyd-Struktur. Die Nat. 1958, 45, 542. [CrossRef]

133. Dachs, V.H. Die Kristallstrucktur Des Bixbyits (Fe,Mn $)_{2} \mathrm{O}_{3}$. Z. Krist. 1956, 107, 370-395. [CrossRef]

134. Sakurai, S.; Namai, A.; Hashimoto, K.; Ohkoshi, S.-I. First Observation of Phase Transformation of All Four Fe $\mathrm{O}_{3} \mathrm{Phases}_{(\mathrm{Gamma}}$ $\rightarrow$ Epsilon $\rightarrow$ Beta $\rightarrow$ Alpha-Phase). J. Am. Chem. Soc. 2009, 131, 18299-18303. [CrossRef] [PubMed]

135. Linnera, J.; Karttunen, A.J. Lattice Dynamical Properties of Antiferromagnetic MnO, CoO, and NiO, and the Lattice Thermal Conductivity of NiO. Phys. Rev. B 2019, 100, 144307. [CrossRef]

136. Risbud, A.S.; Snedeker, L.P.; Elcombe, M.M.; Cheetham, A.K.; Seshadri, R. Wurtzite CoO. Chem. Mater. 2005, 17, 834-838. [CrossRef]

137. Will, G.; Masciocchi, N.; Parrish, W.; Hart, M. Refinement of Simple Crystal Structures from Synchrotron Radiation Powder Diffraction Data. J. Appl. Crystallogr. 1987, 20, 394-401. [CrossRef]

138. Jiang, Z.; Rappe, A.M. Mechanistic Study of the Li-Air Battery with a $\mathrm{Co}_{3} \mathrm{O}_{4}$ Cathode and Dimethyl Sulfoxide Electrolyte. J. Phys. Chem. C 2021, 125, 21873-21881. [CrossRef]

139. Zasada, F.; Piskorz, W.; Sojka, Z. Cobalt Spinel at Various Redox Conditions: DFT+U Investigations into the Structure and Surface Thermodynamics of the (100) Facet. J. Phys. Chem. C 2015, 119, 19180-19191. [CrossRef]

140. Kittel, C. Introduction to Solid State Physics, 6th ed.; John Wiley \& Sons: New York, NY, USA, 1986; ISBN 978-0-471-87474-4.

141. Lide, D. CRC Handbook of Chemistry and Physics, 79th ed.; CRC: Boca Raton, FL, USA, 2005; ISBN 0-8493-0485-7.

142. Åsbrink, S.; Norrby, L.J. A Refinement of the Crystal Structure of Copper(II) Oxide with a Discussion of Some Exceptional e.s.d.'s. Acta Crystallogr. Sect. B Struct. Crystallogr. Cryst. Chem. 1970, 26, 8-15. [CrossRef]

143. Rödl, C.; Sottile, F.; Reining, L. Quasiparticle Excitations in the Photoemission Spectrum of CuO from First Principles: A GW Study. Phys. Rev. B Condens. Matter Mater. Phys. 2015, 91, 045102. [CrossRef]

144. O'Keeffe, M.; Bovin, J.-O. The Crystal Structure of Paramelaconite, $\mathrm{Cu}_{4} \mathrm{O}_{3}$. Am. Mineral. 1978, 63, $180-185$.

145. Heinemann, M.; Eifert, B.; Heiliger, C. Band Structure and Phase Stability of the Copper Oxides $\mathrm{Cu}_{2} \mathrm{O}, \mathrm{CuO}_{\text {, and Cu}} \mathrm{O}_{3}$. Phys. Rev. B Condens. Matter Mater. Phys. 2013, 87, 3-7. [CrossRef]

146. Bolzan, A.; Kennedy, B.; Howard, C. Neutron Powder Diffraction Study of Molybdenum and Tungsten Dioxides. Aust. J. Chem. 1995, 48, 1473. [CrossRef]

147. Rogers, D.B.; Shannon, R.D.; Sleight, A.W.; Gillson, J.L. Crystal Chemistry of Metal Dioxides with Rutile-Related Structures. Inorg. Chem. 1969, 8, 841-849. [CrossRef]

148. Ben-Dor, L.; Shimony, Y. Crystal Structure, Magnetic Susceptibility and Electrical Conductivity of Pure and NiO-Doped MoO 2 and $\mathrm{WO}_{2}$. Mat. Res. Bull. 1974, 9, 837-844. [CrossRef]

149. Rodriguez, E.E.; Poineau, F.; Llobet, A.; Sattelberger, A.P.; Bhattacharjee, J.; Waghmare, V.U.; Hartmann, T.; Cheetham, A.K. Structural Studies of $\mathrm{TcO}_{2}$ by Neutron Powder Diffraction and First-Principles Calculations. J. Am. Chem. Soc. 2007, 129, 10244-10248. [CrossRef] [PubMed]

150. Boman, C.-E.; Danielsen, J.; Haaland, A.; Jerslev, B.; Schäffer, C.E.; Sunde, E.; Sørensen, N.A. Refinement of the Crystal Structure of Ruthenium Dioxide. Acta Chem. Scand. 1970, 24, 116-122. [CrossRef]

151. Ryden, W.D.; Lawson, A.W. Magnetic Susceptibility of $\mathrm{IrO}_{2}$ and $\mathrm{RuO}_{2}$. J. Chem. Phys. 1970, 52, 6058-6061. [CrossRef]

152. Shannon, R.D. Synthesis and Properties of Two New Members of the Rutile Family $\mathrm{RhO}_{2}$ and $\mathrm{PtO}_{2}$. Solid State Commun. 1968, 6 , 139-143. [CrossRef]

153. Shirako, Y.; Wang, X.; Tsujimoto, Y.; Tanaka, K.; Guo, Y.; Matsushita, Y.; Nemoto, Y.; Katsuya, Y.; Shi, Y.; Mori, D.; et al. Synthesis, Crystal Structure, and Electronic Properties of High-Pressure PdF2-Type Oxides $\mathrm{MO}_{2}(\mathrm{M}=\mathrm{Ru}, \mathrm{Rh}, \mathrm{Os}$, Ir, Pt). Inorg. Chem. 2014, 53, 11616-11625. [CrossRef]

154. Richards, R. Surface and Nanomolecular Catalysis, 1st ed.; CRC Press: Boca Raton, FL, USA, 2006; ISBN 978-0-367-39081-5.

155. Standke, B.; Jansen, M. Darstellung Und Kristallstruktur von $\mathrm{Ag}_{3} \mathrm{O}_{4}$. J. Solid State Chem. 1987, 67, 278-284. [CrossRef]

156. Tudela, D. Silver(II) Oxide or Silver(I,III) Oxide? J. Chem. Educ. 2008, 85, 863. [CrossRef]

157. Standke, B.; Jansen, M. $\mathrm{Ag}_{3} \mathrm{O}_{4}$, the First Silver(II,III) Oxide. Angew. Chem. Int. Ed. Engl. 1986, 25, 77-78. [CrossRef]

158. Palmer, D.; Dickens, P. Tungsten Dioxide: Structure Refinement by Powder Neutron Diffraction. Acta. Cryst. 1979, B35, $2199-2201$. [CrossRef]

159. Goodenough, J.B.; Pierre, G.; Jean, B. Magnetic and Electric Properties of $\mathrm{ReO}_{2}$ : Theoretical Investigation. Compt. Rend. 1965, 261, 2331-2335.

160. Gibart, P. Physico-Chemical Properties of Rhenium Dioxides. Bull. Soc. Chim. Fr. 1967, 2, 444.

161. Wang, S.; Liu, Y.; Yu, Z.; Sheng, X.; Yang, S.A. Hourglass Dirac Chain Metal in Rhenium Dioxide. Nat. Commun. 2017, 8, 1844. [CrossRef]

162. Corrêa, H.P.S.; Cavalcante, I.P.; Martinez, L.G.; Orlando, C.G.P.; Orlando, M.T.D. Refinement of Monoclinic ReO 2 Structure from XRD by Rietveld Method Rietveld. Braz. J. Phys. 2004, 34, 1208-1210. [CrossRef] 
163. Magnéli, A.; Siitonen, S.; Skrifvars, B.; Schliack, J.; Reio, L. Studies on Rhenium Oxides. Acta Chem. Scand. 1957, 11, 28-33. [CrossRef]

164. Tribalat, S.; Jungfleisch, J.; Delafosse, D. Sur Les Structures Cristallines Du Dioxyde de Rhenium. C. R. Acad. Sc. Paris 1964, 259, 2109-2112.

165. Ivanovskii, A.L.; Chupakhina, T.I.; Zubkov, V.G.; Tyutyunnik, A.P.; Krasilnikov, V.N.; Bazuev, V.G.; Okatov, V.S.; Lichtenstein, A.I. Structure and Electronic Properties of New Rutile-like Rhenium (IV) Dioxide ReO2. Phys. Lett. Sect. A Gen. At. Solid State Phys. 2005, 348, 66-70. [CrossRef]

166. Bolzan, A.A.; Fong, C.; Kennedy, B.J.; Howard, C.J. Structural Studies of Rutile-Type Metal Dioxides. Acta Crystallogr. Sect. B Struct. Sci. 1997, 53, 373-380. [CrossRef]

167. Ping, Y.; Galli, G.; Goddard, W.A. Electronic Structure of $\mathrm{IrO}_{2}$ : The Role of the Metal d Orbitals. J. Phys. Chem. C 2015, 119, 11570-11577. [CrossRef]

168. Steinmann, S.N.; Corminboeuf, C. Comprehensive Benchmarking of a Density-Dependent Dispersion Correction. J. Chem. Theory Comput. 2011, 7, 3567-3577. [CrossRef] [PubMed]

169. Tkatchenko, A. Current Understanding of Van Der Waals Effects in Realistic Materials. Adv. Funct. Mater. 2015, 25, $2054-2061$. [CrossRef]

170. Stephens, J.S.; Cruickshank, D.W.J. The Crystal Structure of $\left(\mathrm{CrO}_{3}\right) \infty$. Acta Crystallogr. Sect. B Struct. Crystallogr. Cryst. Chem. 1970, 26, 222-226. [CrossRef]

171. Sitepu, H. Texture and Structural Refinement Using Neutron Diffraction Data from Molybdite $\left(\mathrm{MoO}_{3}\right)$ and $\left.\mathrm{Calcite}_{(\mathrm{CaCO}}\right)$ Powders and a Ni-Rich Ni50.7Ti49.30 Alloy. Powder Diffr. 2009, 24, 315-326. [CrossRef]

172. Locherer, K.R.; Swainson, I.P.; Salje, E.K.H. Transition to a New Tetragonal Phase of $\mathrm{WO}_{3}$ : Crystal Structure and Distortion Parameters. J. Phys. Condens. Matter 1999, 11, 4143-4156. [CrossRef]

173. Simon, V.A.; Dronskowski, R.; Krebs, B.; Hettic, B. Die Kristallstruktur von $\mathrm{Mn}_{2} \mathrm{O}_{7}$. Angew. Chem. 1987, 99, 160-161. [CrossRef]

174. Krebs, V.B. Technetium(VIII)-Oxid: Ein Ubergangsmetalloxid Mit Molekulstruktur Im Festen Zustand. Z. Anorg. Allg. Chem. 1971, 380, 146-159. [CrossRef]

175. Pley, M.; Wickleder, M.S. Two Crystalline Modifications of $\mathrm{RuO}_{4}$. J. Solid State Chem. 2005, 178, 3206-3209. [CrossRef]

176. Krebs, B.; Hasse, K.D. Refinements of the Crystal Structures of $\mathrm{KTcO}_{4}, \mathrm{KReO}_{4}$ and $\mathrm{OsO}_{4}$. The Bond Lengths in Tetrahedral Oxoanions and Oxides of $\mathrm{d}^{0}$ Transition Metals. Acta Crystallogr. 1976, B32, 1334-1337. [CrossRef]

177. Grimme, S.; Ehrlich, S.; Goerigk, L. Effect of the Damping Function in Dispersion Corrected Density Functional Theory. J. Comput. Chem. 2011, 32, 1456-1465. [CrossRef] [PubMed]

178. Pušelj, M.; Ban, Z.; Lukačević, E.; Morvaj, J. On the Preparation of Mercuric Peroxides and Refinement of the $\alpha-\mathrm{HgO}_{2}$ Structure. Z. Anorg. Allg. Chem. 1985, 528, 191-194. [CrossRef]

179. Vannerberg, N.G. Formation and Structure of Mercuric Peroxides. Arkiv. Kemi. 1959, 13, 515-521.

180. Hesse, W.; Jansen, M.; Schnick, W. Recent Results in Solid State Chemistry of Ionic Ozonides, Hyperoxides, and Peroxides. Prog. Solid State Chem. 1989, 19, 47-110. [CrossRef]

181. Puselj, M.; Ban, Z.; Lukačević, E. The Crystal Structure of $\alpha$-Mercury(II) Peroxide. J. Appl. Crystallogr. 1983, 16, 357. [CrossRef]

182. Dovesi, R.; Orlando, R.; Erba, A.; Zicovich-Wilson, C.M.; Civalleri, B.; Casassa, S.; Maschio, L.; Ferrabone, M.; De La Pierre, M.; D'Arco, P.; et al. CRYSTAL14: A Program for the Ab Initio Investigation of Crystalline Solids. Int. J. Quantum Chem. 2014, 114, 1287-1317. [CrossRef]

183. Perdew, J.P.; Burke, K.; Ernzerhof, M. Generalized Gradient Approximation Made Simple. Phys. Rev. Lett. 1996, 77, 3865-3868. [CrossRef]

184. Adamo, C.; Barone, V. Toward Reliable Density Functional Methods without Adjustable Parameters: The PBE0 Model. J. Chem. Phys. 1999, 110, 6158-6170. [CrossRef]

185. Weigend, F.; Ahlrichs, R. Balanced Basis Sets of Split Valence, Triple Zeta Valence and Quadruple Zeta Valence Quality for H to Rn: Design and Assessment of Accuracy. Phys. Chem. Chem. Phys. 2005, 7, 3297-3305. [CrossRef]

186. Grimme, S.; Hansen, A.; Brandenburg, J.G.; Bannwarth, C. Dispersion-Corrected Mean-Field Electronic Structure Methods. Chem. Rev. 2016, 116, 5105-5154. [CrossRef]

187. Pascale, F.; Zicovich-Wilson, C.M.; López Gejo, F.; Civalleri, B.; Orlando, R.; Dovesi, R. The Calculation of the Vibrational Frequencies of Crystalline Compounds and Its Implementation in the CRYSTAL Code: Crystalline Compounds and the CRYSTAL Code. J. Comput. Chem. 2004, 25, 888-897. [CrossRef] [PubMed]

188. Zicovich-Wilson, C.M.; Pascale, F.; Roetti, C.; Saunders, V.R.; Orlando, R.; Dovesi, R. Calculation of the Vibration Frequencies of A-Quartz: The Effect of Hamiltonian and Basis Set. J. Comput. Chem. 2004, 25, 1873-1881. [CrossRef] [PubMed]

189. Zagorac, D.; Müller, H.; Ruehl, S.; Zagorac, J.; Rehme, S. Recent Developments in the Inorganic Crystal Structure Database: Theoretical Crystal Structure Data and Related Features. J Appl Cryst. 2019, 52, 918-925. [CrossRef] [PubMed]

190. Grazulis, S.; Chateigner, D.; Downs, R.T.; Yokochi, A.F.T.; Quiros, M.; Lutterotti, L.; Manakova, E.; Butkus, J.; Moeck, P.; Le Bail, A. Crystallography Open Database-an Open-Access Collection of Crystal Structures. J. Appl. Crystallogr. 2009, 42, 726-729. [CrossRef]

191. Grazulic, S.; Daskevic, A.; Merkys, A.; Chateigner, D.; Lutterotti, L.; Serebryanaya, N.R.; Moeck, P.; Downs, R.T.; Le Bail, A. Crystallography Open Database (COD): An Open-Access Collection of Crystal Structures and Platform for World-Wide Collaboration. Nucleic Acids Res. 2012, 40, 420-427. [CrossRef] 
192. Momma, K.; Izumi, F. VESTA 3 for Three-Dimensional Visualization of Crystal, Volumetric and Morphology Data. J. Appl. Cryst. 2011, 44, 1272-1276. [CrossRef]

193. Freund, H.J.; Pacchioni, G. Oxide Ultra-Thin Films on Metals: New Materials for the Design of Supported Metal Catalysts. Chem. Soc. Rev. 2008, 37, 2224-2242. [CrossRef] 